\title{
Legal Problems Aspects of the Immunity and Its Impact On Criminal Responsibility According to Omani Legislation
}

\author{
Saud Muhammad Al-Azri*, Abidah Abdul Ghafar \\ Faculty of Syariah and Law, Islamic Science University of Malaysia (USIM), Nilai, Malaysia \\ * suazri82@hotmail.com
}

KEYWORDS: $\quad$ Problems of Immunity, Criminal Responsibility, The Omani Legislator.

Crossref doi) https://doi.org/10.51345/.v32i4.454.g244

\begin{abstract}
:
The study discusses the legal problem of immunities that affected the criminal responsibility of individuals in the Omani judiciary. Undoubtedly, this is due to a legislative shortcoming on the one hand and a misunderstanding on the other hand of the provisions of immunity, which contributed to its exploitation, abuse and invocation as a vehicle for the commission of personal crimes, as well as On the problems arising originally from deciding the immunity of certain categories of state employees, which led to their conflicting interests with the interests of the victim, and their impunity. Therefore, the researcher will explain the aspects of the Omani legislator's treatment of immunity and the texts it decided starting from the basic system of the state issued by decree Royal Decree No. (101/96) and repealed with the issuance of the statute in force under Royal Decree No. (6/2021), then other laws, regulations and decisions implementing them, dealing with the concept of immunity, its types, legal nature and basis, and the problems arising from it. By extrapolating the provisions of immunity in Omani legislation and its applications, it became clear to the researcher that there are some shortcomings in its organization, which contributed to its misunderstanding and exploitation and sharpened the idea of immunity for what it was decided for, as well as the existence of practical problems of immunity that affected criminal responsibility, on a shift that calls for reconsideration and the categories that decided Despite the legislator's intervention by Royal Decree No. (3/2014) regarding defining the concept of immunity and the scope of its application, the need is still urgent to find a more accurate regulation and more precise provisions clarifying the issue of immunity, in addition to the necessity of restricting its use without the current uses.
\end{abstract}




\title{
الإشكاليات القانونية المتزتبة على الحصانة وأثرها على المسؤولية الجنائية وفق التشريع العماني
}

\author{
سعود بن محمد بن سلطان العزري*، د. عبيدة بنت عبد الففار \\ كلية الشريعة والقانون، جامعة العلوم الإسلامية الماليزية، نيلاي، ماليزيا \\ *suazri82@hotmail.com
}

الكلمات المفناحية إشكاليات الحصانة، المسؤولية الجنائية، المشرع العماني.

Crossref doi https://doi.org/10.51345/.v32i4.454.g244

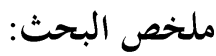

تناقش الدراسة مشكلة قانونية الحصانات التي أثرت على المسؤولية الجنائية للأفراد في ساحة القضاء العماني، ولاشك أن ذلك راجع إلى وجود قصور تشريعي من جهة وسوء فهم من جهة أخرى لأحكام الحصانة، أسهم في استغلالها وإساءة استعمالها والتذرع بما كمطية لارتكاب جرائم شخصية، فضلا عن الإشكاليات المترتبة أصلا على تقرير الحصانة لفئات معينة من موظفي الدولة، أدى في لتضارب مصالحهم مع مصالح المعتدى عليهم، وإفلاتم من العقاب. لذا حرص الباحث على بيان أوجه معالجة المشرع العماني للحصانة، والنصوص التي قررتا ابتداء من النظام الأساسي للدولة الصادر بالمرسوم السلطاني رقم (96/101) والملغي بصدمور النظام الأساسي المعمول به حالياً بموجب المرسوم السلطاني رقم (2021/6) ثم القوانين الأخرى واللوائح والقرارات المنفذة لما.

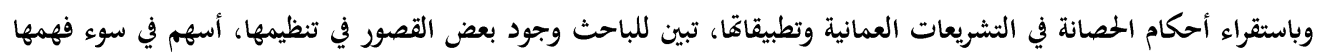

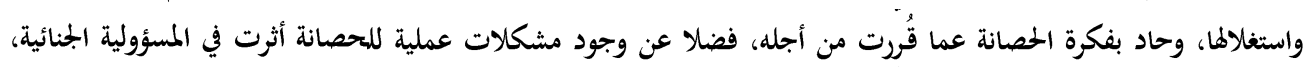

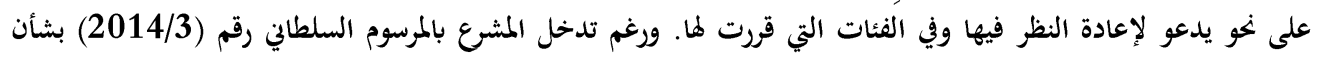
تحديد مفهوم الحصانة ونطاق تطبيقها، إلا إن الحاجة ما تزال ملحة لإيجاد تنظيم أكثر دقة وأحكام أكثر إحكام مبينة لموضوع الحصانة فضلا عما اقتضته ضرورة الحال من تضييق استخدامها.

المقدمة:

الدعوى العمومية هي الوسيلة التي يقتضي بها المجتمع حقه من الجاني الذي ارتكب فعلاً مجرماً بموجب نص قانوخي، بواسطة جهة أوكل لما المشرع مسؤولية ذلك، تختلف مسمياتا من نظام قانوني لآخر، وعرفها التشريع العماني باسم الادعاء العام، إذ قرر النظام الأساسي للدولة الصادر بالمرسوم السلطاني رقم (2021/6) في مادته ال(86) بأن: (الادعاء العام جزء من السلطة القضائية، يتولى الدعوى العمومية باسم الجمتمع..)، كما قررت المادة (4) من قانون الإجراءات الجزائية المعدل بأنه: (يختص الادعاء العام برفع الدعوى العمومية ومباشرقا أمام المكمة المختصة..). فالادعاء العام هو الأمين على الدعوى العمومية وهو 
من يتولاها باسم الجمتمع، والأصل أن له مطلق الحرية في ذلك، وأنه هو دون سواه يختص بتقدير أمر

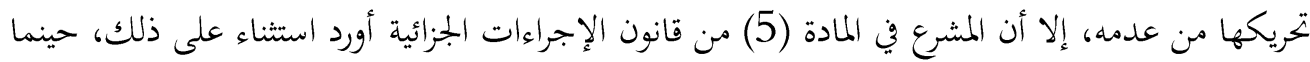
قرر بأنه لا يجوز رفع الدعوى العمومية في حالتين؛ الأولى: بناء على شكوى شفهية أو كتابية من المجني عليه

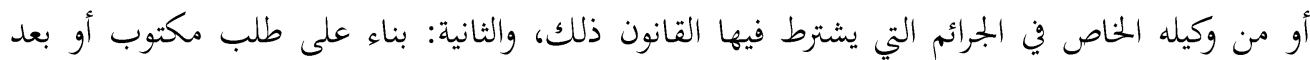
الحصول على إذن كتابي من الجهة المختصة في الجرائم التي يشترط فيها القانون ذلك، ولعل من من أبراء تطبيقات الحصول على الإذن ما يعرف بالحصانة. وحديثا، فبالإضافة للتشريعات التي سنتها مختلف دول العالم فقد برزت العديد من الاتفاقيات الدولية نظمت الحصانة وإجراءاتها، لعل أبرزها اتفاقية امتيازات وحصانات منظمة الأمم المتحدة لعام 1946، لإنيات

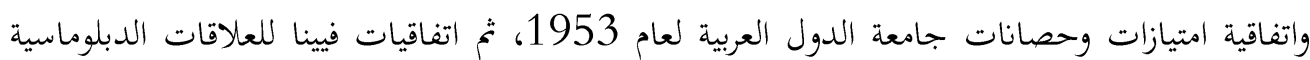
والقنصلية والبعثات الخاصة لأعوام 1961 و1963 و1969 على التوالي، وبعدها الاتفاقية التي أبرمتها الأمم المتحدة في سنة 1973م بشأن منع ومعاقبة الجرائم التي ترتكب ضد الأشخاص المشمولين بالحماية الدولية، مما يتجلى لنا بأن حصانة مثثلي الدول هي أولى أنواع الحصانات ظهوراً في تاريخ البشرية وأبرزها تطبيقا.

ومن جهة أخرى فإن للحصانة أثار سلبية ونتائج وخيمة تلقي بضلالها على الجمتمع متى ما تم التوسع فيها

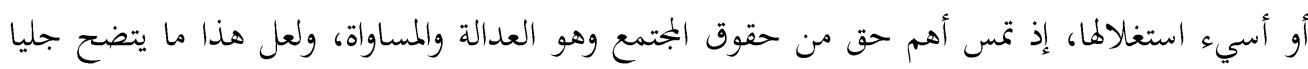

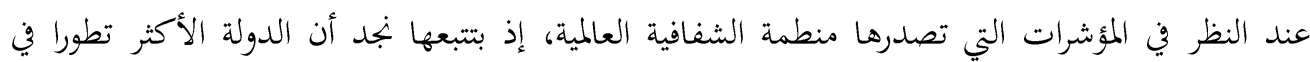
قوانينها وأنظمتها تأتي في مرتبة متقدمة على صعيد التصنيف الدولي، بينما تأتي الدول النامية خصوصها في تئي قاع الترتيب، وذلك لوجود زيادة مضطردة في حجم الممارسات التي تنطوي تحت مفهوم الجريمة لعوامل عدة

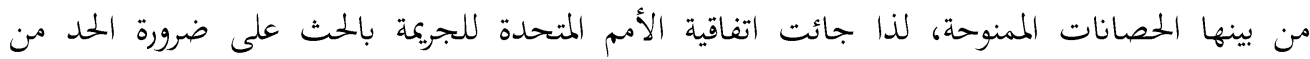
الحصانات في التشريعات الداخلية. وفي سلطنة عمان؛ فإن المشرع العماني قد قرر ونظم الحصانة الجنائية، بموجب قوانين عدة، ابتداء من أب

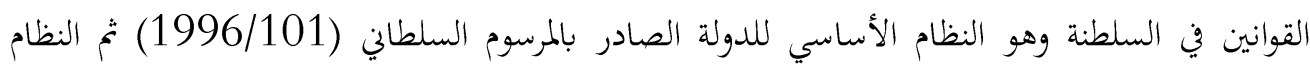
الأساسي الجديد الصادر بالمرسوم السلطاني رقم (2021/6)، إذ قرر الأخير في مادته (48) حصانة سلطان البلاد بقوله: "السلطان رئيس الدولة والممثل الأسمى لها، والقائد الأعلى، ذاته مصونة لا تمس، واحترامه واجب، وأمره مطاع، وهو رمز الوحدة الوطنية والساهر على رعايتها وحمايتها"، فضلا عن القوانين الأخرى ذات الصلة والتي نظمت أنواع الحصانة الأخرى وفق ما سيأتي ذكره لاحقا. 
ومؤخرا؛ وإزاء بروز بعض الممارسات الخاطئة في تطبيق مفهوم الحصانة والتعسف فيها؛ صدر المرسوم

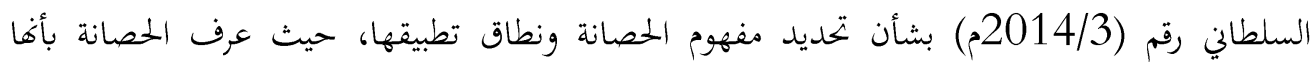
مجموعة الضمانات والامتيازات المقررة للمتمتعين بها بصفاقم وليس بأشخاصهم بغرض تمكينهم من القيام بواجبات وظائفهم أو أداء الحخدمة العامة الموكولة إليهم وليست امتيازا شخصيا بقصد إعفائهم من المسؤولية دون مسوغ. كما حدد نطاق الحصانة على ما يصدر عنهم من أقوال وأفعال بسبب أو بمناسبة ممارسة اختصاصاةم وفي الحدود المقررة لها.

\section{مشكلة الدراسة :}

الحصانة هي استثناء من الأصل العام، القاضي بأن كل الناس سواسية أمام القانون، والمشرع عندما قررها

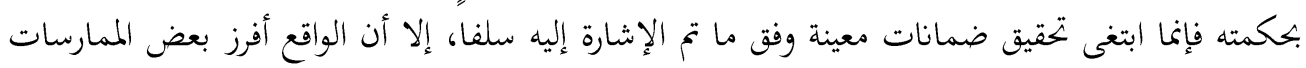

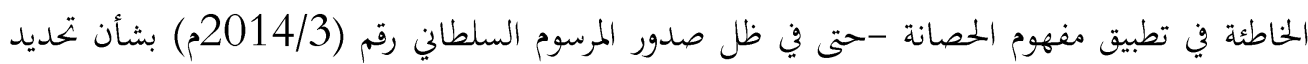
مفهوم الحصانة ونطاقها، ترتب عنه المساس بالأمن والنظام العام والنيل من حقوق المعتدى عليهم إما بعدم

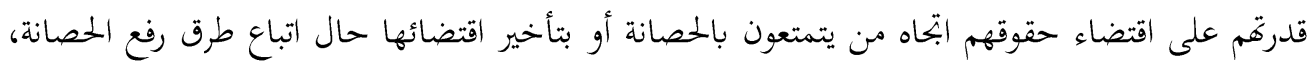

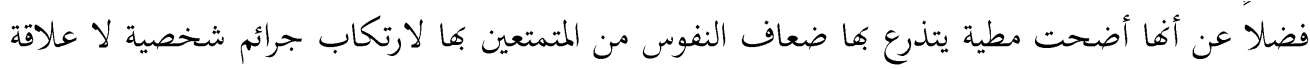
لها بوظيفتهم.

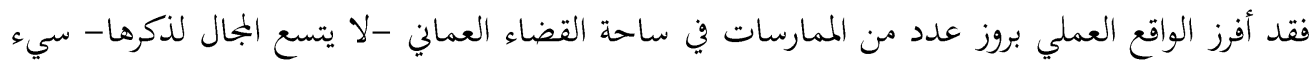

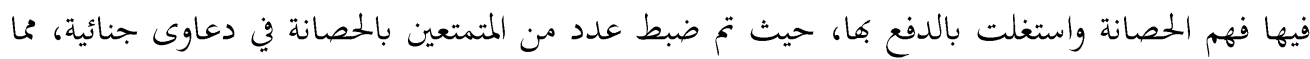

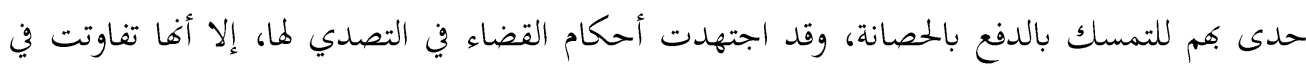
تقديرها والحكم بها، مما نتج عنه إفلات البعض من العقوبة المقررة.

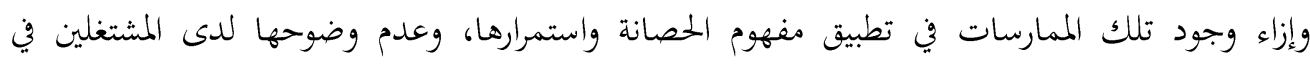

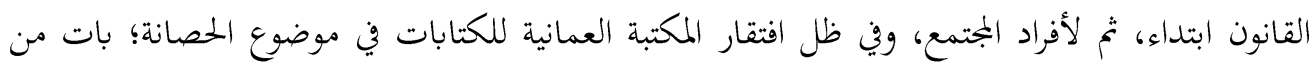
الضرورة بمكان وجود دراسات وأبحاث تتطرق للموضوع بشكل معمق وموسع، تبسط مفهوم الحصانة وحدودها ونطاقها، وإجراءات رفعها، والإشكاليات المترتبة عليها، فجاء بحثنا الماثل في سبيل ذلك.

\section{أهداف الدراسة:}

أ. الوقوف على نصوص التشريعات العمانية المنظمة للحصانة، ومدى ملائمتها ركفايتها وأوجه القصور فيها. 
ب. مناقشة الإشكاليات العملية للحصانة ومدى تأثيرها على المسؤولية الجنائية.

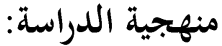

بما أن المنهج الوصفي التحليلي يهتم بدراسة الظاهرة كما هي في الواقع، ووصفها وصفا دقيقا، وجمع

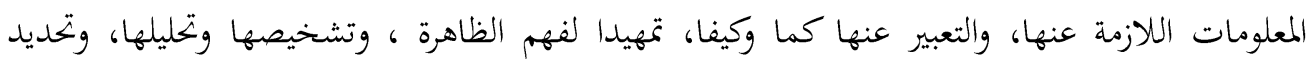

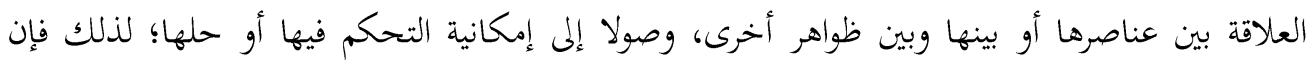

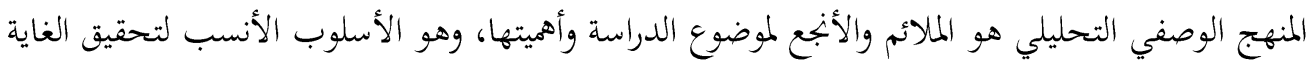
المبتغاة منها.

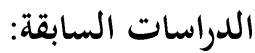

دراسة عكاشة، (2005) هدفت شرح قانون الإجراءات المدنية والتجارية العماني. شرح فيه الكاتب نصوص قانون الإجراءات الجزائية العماني، والتي من بينها النصوص الخاصة بالقبض والتفتيش والتحقيق والماكمة.

وبذلك يعتبر المعين الأساسي لدراستي الماثلة في بيان طبيعة الإجراءات الجزائية المعمول بها في السلطنة حال وقوع جريمة معينة، وتحدث بشكل عابر فقط عن دعاوى الإذن في القيود على سلطة الادعاء العام في

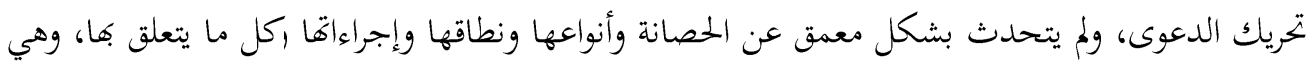
مشكلة البحث في دراستي الماثلة، والتي سوف أسعى لتغطيتها فيها. دراسة الصقري، (2011) ناقش الكاتب الحصانة القضائية في السلطنة، وتناول فيها أهمية القضاء وأهمية تمتع القضاة بالحصانة حتى يقوموا بأداء أعمالهم بكل نزاهة وحياد، ثم تحدث عن ماهية الحصانة التي يتمتع

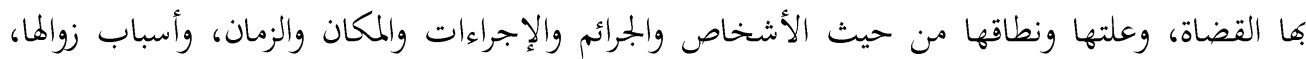

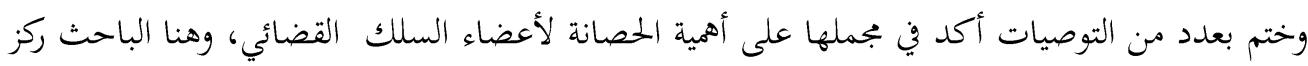
على نوع واحد فقط من أنواع الحصانة التي سوف تتناولها دراستي وهي الحصانة القضائية فقط، وبالتالي سوف أسعى لتغطية بقية أنواع الحصانة، كما أن الباحث لم يقارن الحصانة القضائية في التشريع العماني بالشريعة الإسلامية وأي من القوانين الأخرى، وهذا ما سوف أغطيه في دراستي بغية إيجاد تأصيل متين للحصانة في التشريع العماني.

دراسة حرب.(2014) أثر الحصانة على المسؤولية الجنائية في الفقه الإسلامي: دراسة فقهية قانونية مقارنة. المجلد 41. العدد 1. وهو بحث سلط فيه الكاتبان الضوء على مسألة الحصانة الممنوحة 
للدبلوماسيين ومن هم في حكمهم كالرؤساء والوزراء والنواب، من حيث نطاقها وأثرها، ومدى مسؤوليتهم

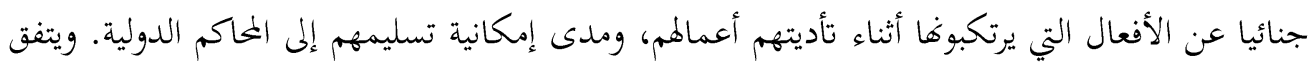

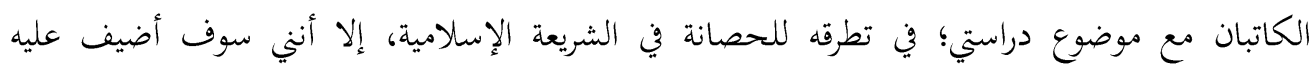
الحصانة في التشريع العماني وأقارغا بها وبالقانون المصري. دراسة الأسدي، (2010) بحث تناول فيه الكاتب موضوع الجريمة الدولية والمسؤولية الجنائية لرئيس الدولة في نظرية المسؤولية الدولية، كما تحدث عن التطور التاريخي للمسؤولية الجنائية الفردية لرئيس الدولة، ومشكلة الدفع بالحصانة لاستبعاد المسؤولية الجنائية لرئيس الدولة. وبالتالي فإن الباحث هنا اقتصر على لحئي

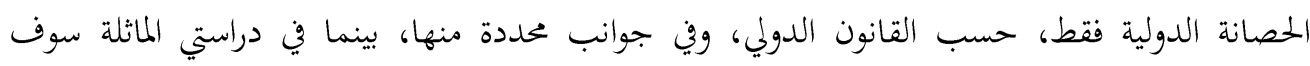
أتحدث عن كل أنواع الحصانات وفقا للتشريع العماني، وأقارغا بأحكام الشريعة الإسلامية، وبالقانون المصري.

دراسة أبو شكيوات، (2014) تناول فيها الباحث مفهوم الحصانات والامتيازات الدبلوماسية الممنوحة للمبعوث الدبلوماسي في الشريعة الإسلامية والقانون الدولي، والأساس القانوني والفقهي لها، وأثرها على لئى

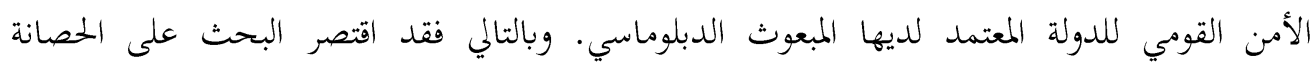
الدبلوماسية فقط وفي الشريعة الإسلامية والقانون الدولي، وتطرق لمواضيع محددة تمثلت في مفهومها

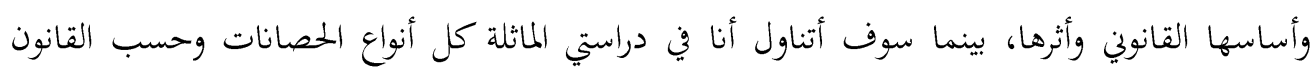
العماني والشريعة الإسلامية والقانون المصري.

\section{منهج البحث:}

اعتمد المنهج الوصفي التحليلي الذي يهتم بدراسة الظاهرة كما هي في الواقع، ووصفها وصفا دقيقا، وجمع

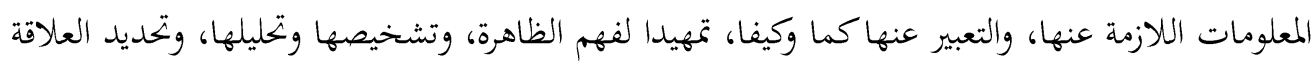

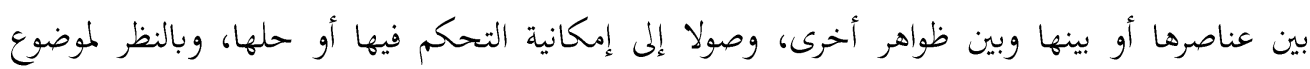
البحث وأهميته؛ فلاشك أن المنهج الوصفي التحليلي هو الأسلوب الأنسب لتحقيق الغاية المبتغاة منه، وهو

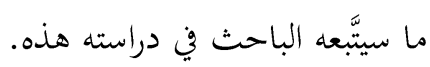

\section{المبحث الأول: الحصانة في التشريع العمالي}

إن الحديث عن الحصانة في التشريع العماني والإشكاليات القانونية المترتبة عليها وأثرها على المسؤولية الجنائية هو أساس بحثنا هذا وجوهره، لذا سوف نخوض في هذا المبحث بإيجاز غمار تنظيم المشرع العماني 
للحصانة في مختلف قوانينه، من حيث مفهوم الحصانة في التشريع العماني، والطبيعة القانونية لما، وأنواعها، ونطاقها.

\section{المطلب الأول: مفهوم الحصانة في التشريع العماني}

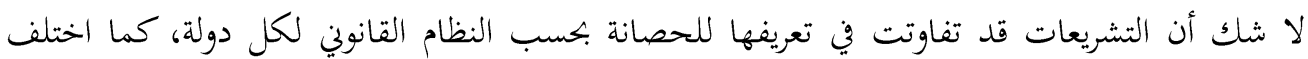
فقهاء القانون وشراحه في تحديد المفهوم القانوني للحصانة، وفق ما تم الإشارة إليه سلفا، وقد أسهم ذلك تلك

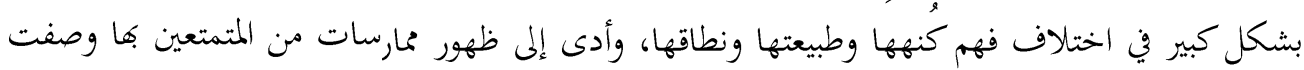

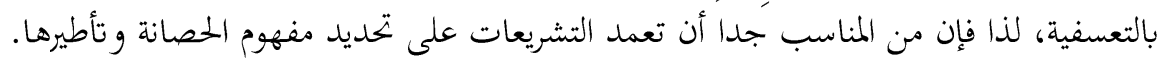

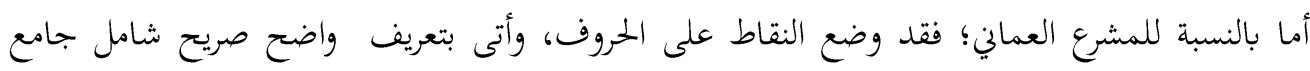
ومانع للحصانة، وذلك بما قرره المرسوم السلطاني رقم (2014/3م) الصادر بتاريخ (9 يناير 2014م) في مادته الأولى؛ حيث نص على أنه: (يقصد بالحصانة التي يقررها المشرع لبعض موظفي الدولة وأعضاء

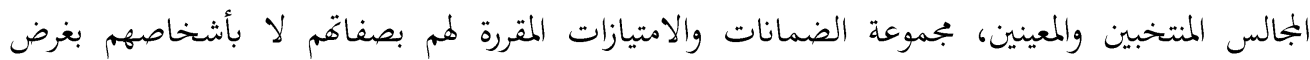

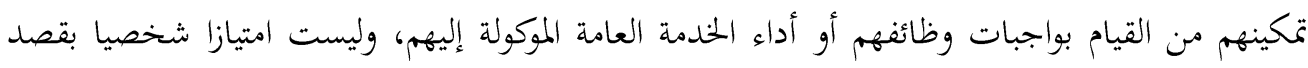

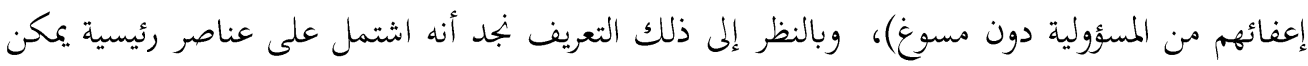

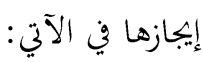
1- أن الحصانة يجب الخب أن تكون مقررة من المشرع، وإقرار المشرع لأمر ما وإفصاحه عن رغبته دائما ما يكون بناء على قانون، على اختلاف درجاته، إذ يستوي أن يكون ذلك الإقرار في النظام الأساسي

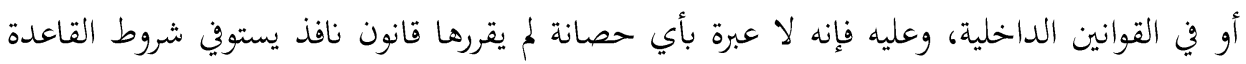
القانونية المستقر عليها في الفقه والقانون.

2- أن الحصانة عبارة عن جملة الضمانات والامتيازات قررت لبعض موظفي الدولة، مما يدلل على أثها أدوات ووسائل تكفل الحماية لموظف الدولة من أي تعرض أو تدخل يمكن أن يؤنثر في أداء الوظيفة فئنة

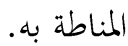

3- أن تلك الحصانة قررت للموظفين بصفاتم لا بأشخاصهم، بمعنى أن الموظف يتمتع بالحصانة بناء على ملى

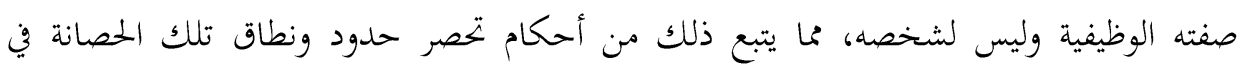

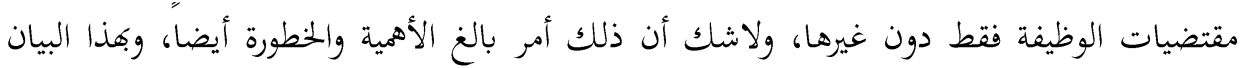

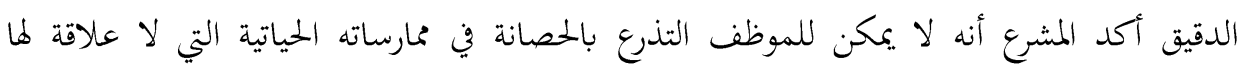
بوظيفته. 
4- أن الحصانة قررت للموظفين بغرض تمكينهم من القيام بواجبات وظائفهم أو أداء الحدمة الموكولة

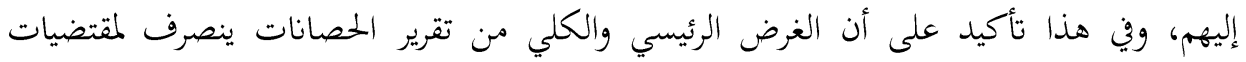
الوظيفة العامة بحسب طبيعتها وضمان أدائها على الوجه الأكمل، باستقلال وحياد ونزاهة تامة.

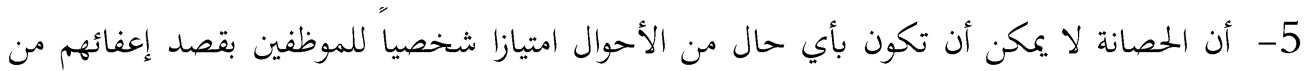
المسؤولية، وهنا تصريح وتصويب لما قد يهيد من فكر وممارسة في تفسير مقصد المشرع من تقرير

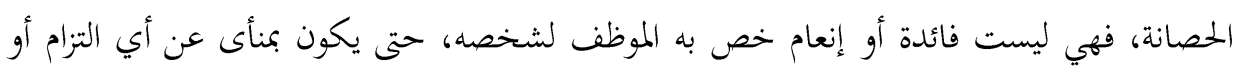

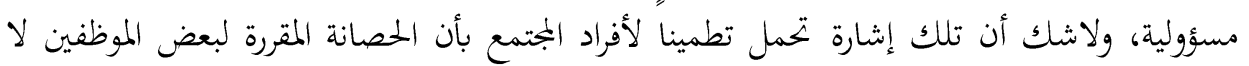
يمكن بأي حال أن تعفيهم من التزاماقم ومسؤولياقم.

\section{المطلب الثالي: الطبيعة القانونية للحصانة في التشريع العماني}

لقد اختلف فقهاء القانون في آرائهم حول الطبيعة القانونية للحصانة، الإجرائية أو الموضوعية أو من حيث طبيعة الدفع بها، كما اختلفت تبعا لذلك توجهات التشريعات المعاصرة حسب النظام القضائي لكلا منها، وفيما يتعلق بالمشرع العماني، فإن القوانين المنظمة للحصانة لم تتطرق صراحة للطبيعة القانونية لها، إلا أنه

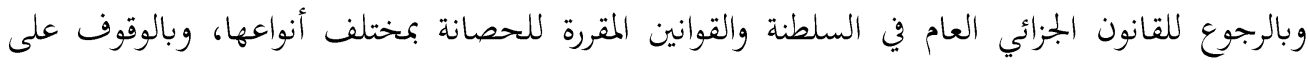
الممارسات القضائية؛ يمكن أن نستخلص ما يأتي: أولاً: بالنسبة للحصانة الموضوعية:

وهي التي تنصرف إلى الجرائم التي قد تنشأ أثناء ممارسة الموظف لوظيفته أو بمناسبتها، وين هذا الشأن نجد

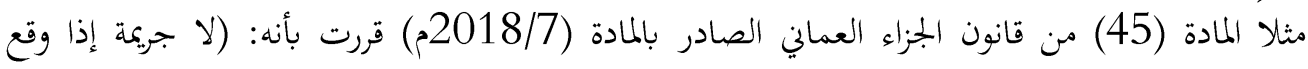

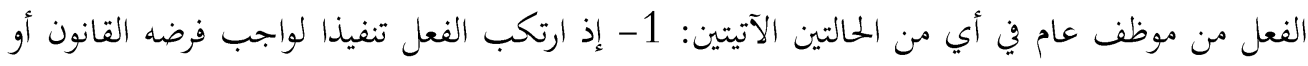
فرضه أمر شرعي صادر عن السلطات المختصة. 2- إذا ارتكب الفعل بحسن نية تنفيذا للقانون)، كما أن المادة (28) من قانون مجلس عام الصادر بالمرسوم السلطاني رقم (2021/7م) نصت عن على على أنه: (لا بتحوز

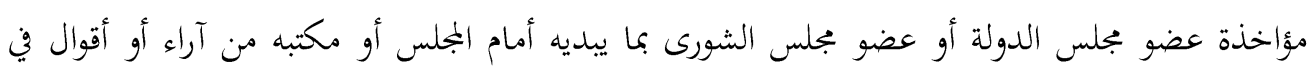
الأمور التي تدخل في اختصاصات المجلس)، وهكذا بالنسبة للحصانات الأخرى. وباستقراء مؤدى النصوص ومقاربتها بالنصوص المشابهة في تشريعات الدول الأخرى وفق ما سبق بيانه؛

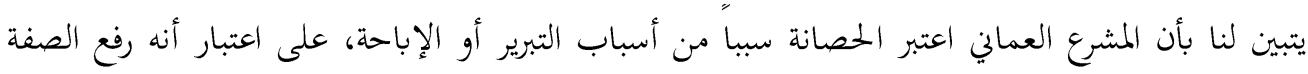

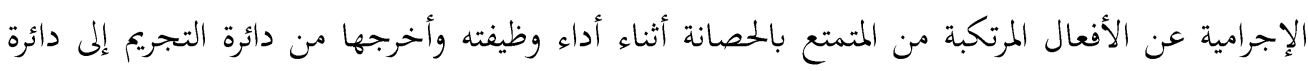
الإباحة. 
ثانيا: بالنسبة الحصانة الإجوائية:

وهي التي يراد بها الإجراءات المتخذة في مواجهة الموظف المتمتع بالحصانة حال ارتكابه جرم معين؛ وهنا

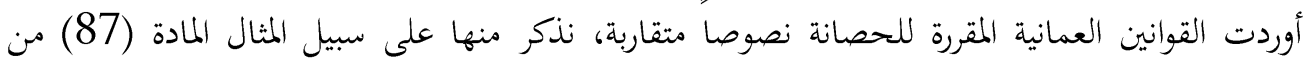
قانون السلطة القضائية مقروءة: (في غير حالات التلبس بالجريمة، لا يجوز إلقاء القبض على القاضي أو

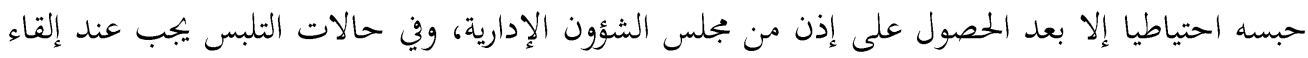

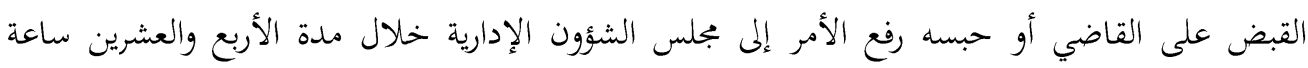
التالية. وللمجلس أن يقرر بعد سماع أقوال القاضي إما الإفراج عنه بكفالة أو بغير كفالة وإما استمرار حبسه لمدة يحددها، وله مع مراعاة الإجراء السابق بتحيد هذه المدة)، وأردفت المادة (88) قائلة: (لا يجيوز اتخاذ إجراءات التحقيق أو رفع الدعوى العمومية على القاضي إلا باذن من مجلس الشؤون الإدارية، بناء على طلب من المدعي العام)، وعلى هذا النهج سارت جميع النصوص المقررة لأنواع الحصانات الأخرى في التشريع العماني مع اختلاف محدود في الضوابط والتنظيم. وبالوقوف على النصوص أعلاه، ومقاربتها بالتشريعات الأخرى وشروحات الفقهاء وفق ما سبق بيانه؛

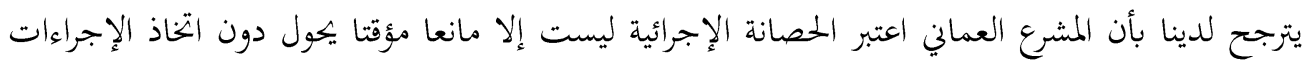

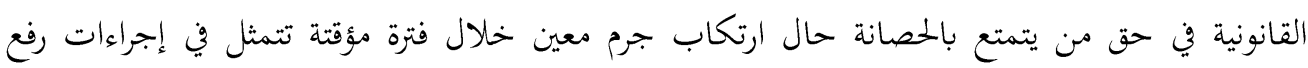
الحصانة.

وليس أدل على ذلك مما قرره المرسوم السلطاني رقم (2014/3) في مادته الثالثة حينما قال: (يحظر على الموظف وعضو المجلس المنتخب أو المعين إساءة استغلال الحصانة المقررة له بصفته، كما يحظر عليه

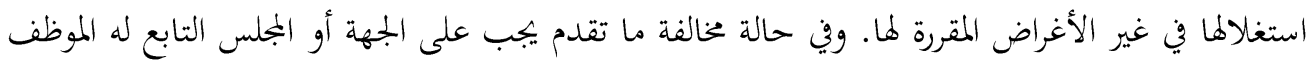

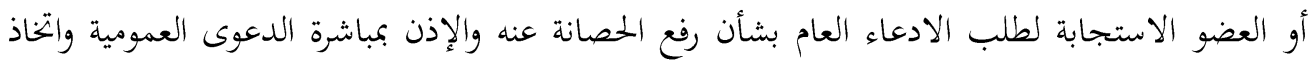

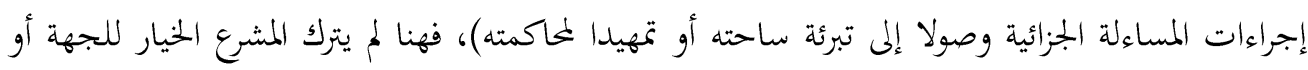

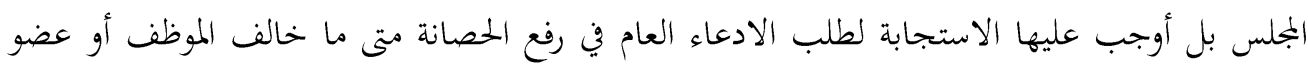

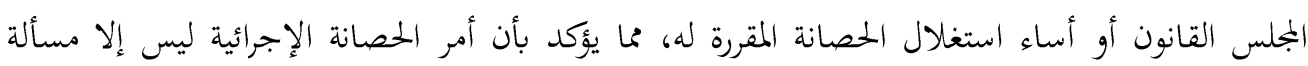
وقتية يتعين فيها اتباع إجراءات معينة لمساءلة الموظف المتمتع بما.

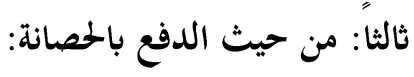
يعرف الدفع بأنه وسيلة قانونية إجرائية يهدف من خلالها المدعى عليه رد ادعاء خصمه، ومنع الحكم له به لهانه

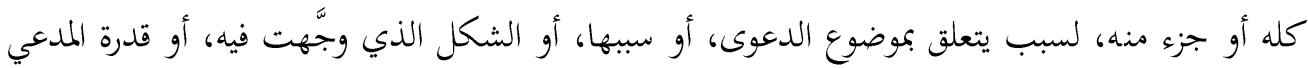


على توجيهها، أو صلاحية المحكمة لنظرها. والدفوع إما أن تكون شكلية وهي المتعلقة بشكل الدعوى، وتنقسم لقسمين؛ الأولى متعلقة بالنظام العام وهي التي لا يترتب على التحدث في موضوع الدعوى سقوط

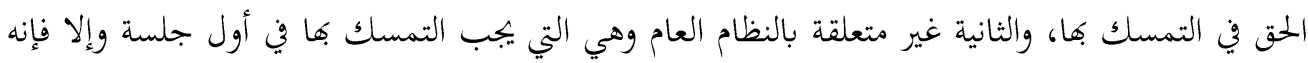
يسقط الحق فيها بعد الحديث في موضوع الدعوى. أما الدفوع الموضوعية فلا تخضع لتلك القاعدة، وبالتالي فيمكن إبداؤها في أي وقت وأي حالة تكون عليها الدعوى قبل غلق باب المرافعة فيها.

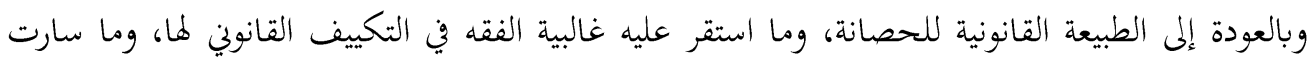
عليه أغلب التشريعات في ذلك؛ فإنه يتبين لنا بأن الدفع بالحصانة يعتبر من الدفوع التي تتعلق بشكل

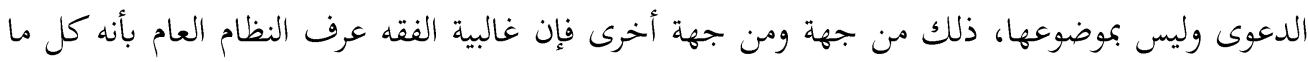
يمس الدولة في كياها أو يتعلق بمصلحة عامة أساسية من مصالحها السياسية أو الاجتماعية أو أورئ الاقتصادية(1)، ومن ثم فإنه إذا ما رجعنا إلى القواعد القانونية والفقهية المنظمة للحصانة، وما قرره المشرع المعانه

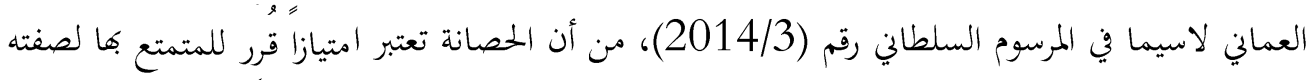
الوظيفية وليس لشخصه؛ فإنه يتأكد لنا بأن الحصانة تتعلق بالنظام العام. ولاشك أنه يترتب على اعتبار الحصانة القضائية من النظام العام علَّة نتائج جوهرية أهمها(2):

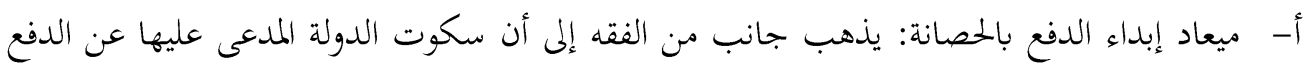
بالحصانة القضائية وترافعها مباشرة في موضوع الدعوى يفيد تنازها عن الحصانة القضائية المقررة

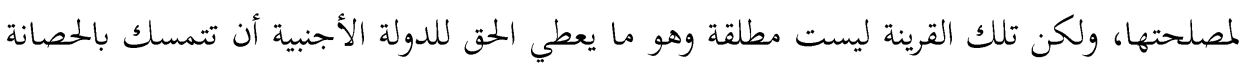

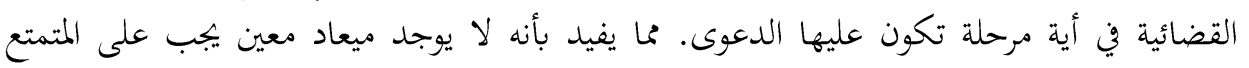

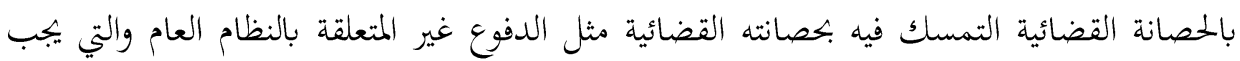
إبداؤها قبل التحدث في موضوع الدعوى القضائية، وبالتالي فإنه يمكن إبداء الدفع بالحصانة في أي مرحلة تكون فيها الدعوى قبل صدور حكم بات فيها. ب-التنازل عن الدفع بالحصانة القضائية: يذهب رأي في الفقه إلى جواز التنازل عن الدفع بالحصانة القضائية من قبل المتمتع بها، شريطة أن يكون هذا التنازل قاطعا ومؤكدا، كما اشترط البعض في بأي التنازل أن يكون صريحا إلا أن ذلك يخالف الواقع وبالتالي فيجوز أن يكون التهن التنازل عن الحصانة

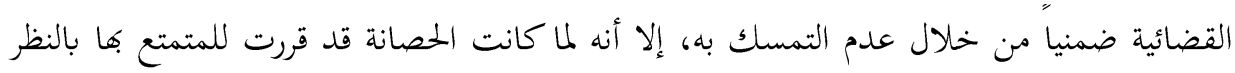
لصفته الوظيفية وليس لذاته فإنه وكنتيجة حتمية لذلك لا يمكن للمتمتع بالحصانة التنازل عنها بشخصه، إلا باذن جهة العمل التي ينتمي إليها، لا سيما في حالة تمتع الشخص بالحصنيه لبهانة القضائية 
نيابة عن دولته مثل رئيس الدولة أو الممثلين الدبلوماسيين وغيرهم، فهنا يجب أن يصدر التنازل من الدولة أو من المتمتع بالحصانة بعد موافقة دولته. ج- من حق المحكمة أن تقضي بالخصانة القضائية من تلقاء نفسها:

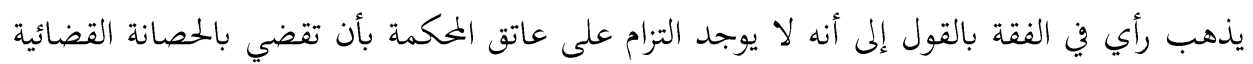

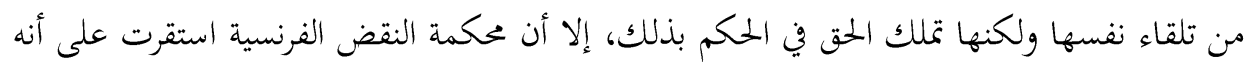

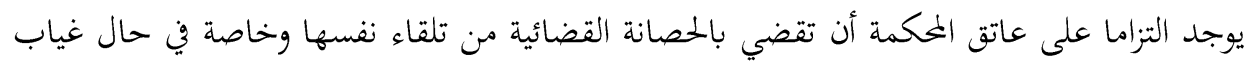

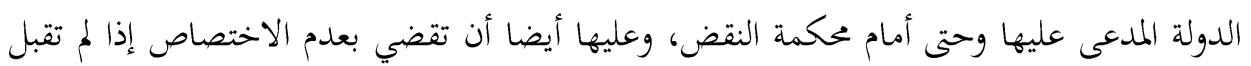

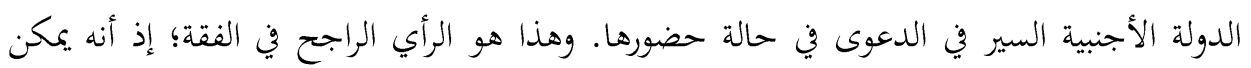
للمحكمة أن تتصدى وتقضي بالحصانة من تلقاء نفسها دون تمسك صاحب الحق فيها أو أو إبداء دفعه بما.

وبعد تبيان خصائص الدفع بالحصانة القضائية، والوقوف على آراء الفقهاء وتوجهات التشريعات المعاصرة، وتعريها على ما سبق وتطرقنا له في موضوع طبيعة الدفع في الحصانة في التشريعات الوضعية من تعدد

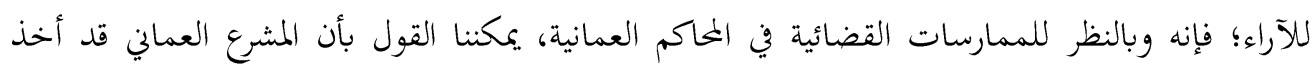
بالرأي الراجح في الفقه معتبرا الدفع بالحصانة القضائية دفعاً بعدم قبول الدعوى العمومية.

\section{المطلب الثالث: أنواع الحصانة في التشريع العماني}

باستقراء التشريعات العمانية والاتفاقيات والمعاهدات التي وقعت عليها السلطنة؛ يمكن القول بأن للحصانة

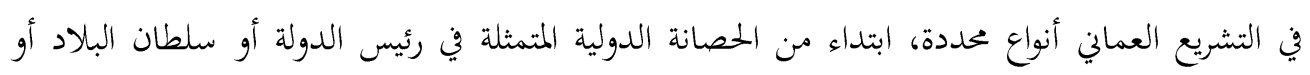

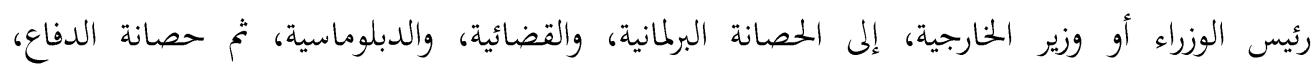

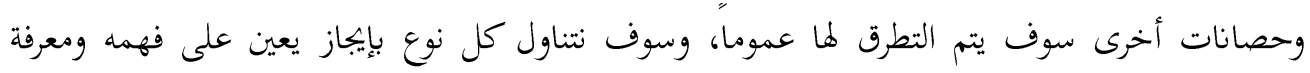
حدوده، وذلك وفق الآتي:

\section{حصانة رئيس الدولة أو سلطان البلاد:}

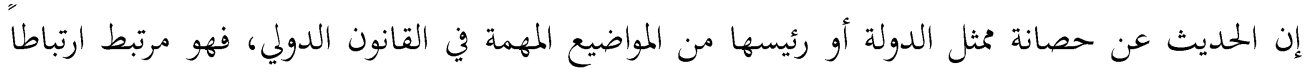

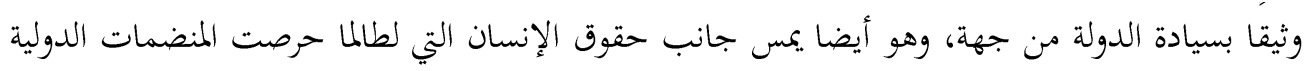
والحقوقية على رعايتها، ولذلك فإن حصانة رئيس البلاد يقع وسط تصادم أسمى مبدأين من مبادئ القانون

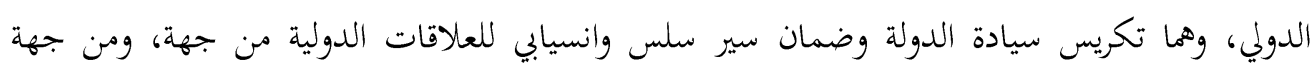
أخرى الحاجة لحماية حقوق الإنسان ومنع منتهكيها من الإفلات من العقاب، خاصة في خضم التطورات 
المستمرة التي شهدها القانون الدولي في ميدان حقوق الإنسان خلال النصف الثاني من القرن الماضي

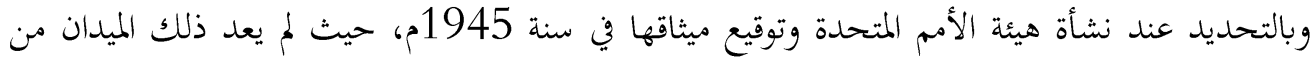
الميادين المحفوظة للدولة والمرتبط بسيادتا، وبعدها أبرمت العديد من الاتفاقيات والمعاهدات الدولية في ذلك ولك الشأن لعل أبرزها اتفاقيات جنيف المبرمة في أعوام (1949، 1966، 1984 و 1964 و2006)، وقد وقعت عليها أغلب دول العالم، بما فيها السلطنة. وفي ذلك قررت محكمة العدل الدولية في عدد من قضاياها لاسيما قضية (يروديا ندومباسي) الحصانة لبعض كبار مثثلي الدولة مثل رؤساء الدول ورؤساء الحكومات ووزراء الخارجية، بقوها: (من الثابت والراسخ في القانون الدولي أن مسؤولين معينين في الدولة يحملون رتبا رفيعة المستوى كرئيس الدولة ورئيس الحكومة ولنداء

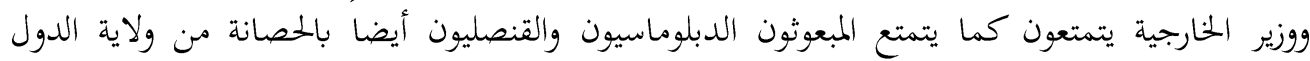

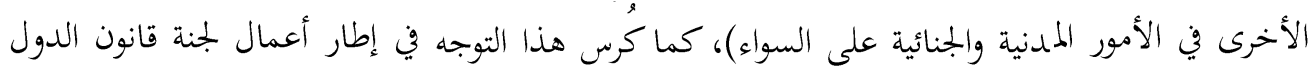

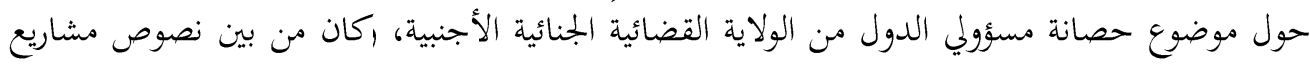

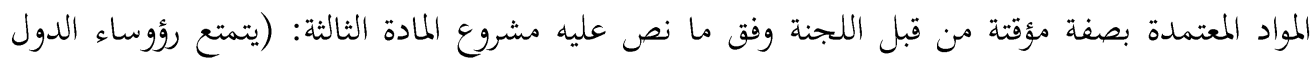

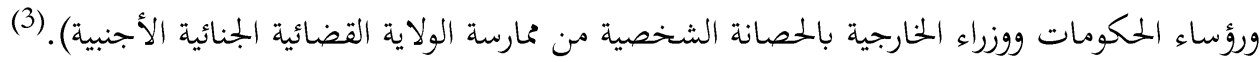
وباستقراء نصوص التشريعات العمانية؛ نجد أفها لم تتطرق لخصانة رئيس البلاد بشكل مباشر، على على اعتبار

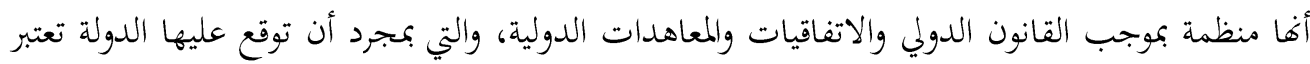
وكأها جزء من قانوغا الداخلي، وتعتبر ملزمة لها من جهة في إطار حصانة رؤساء الدول الأجنبية أثناء

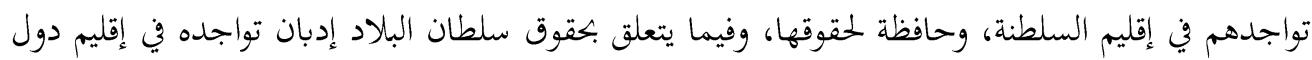
أخرى موقعة على تلك الاتغاقيات. وفيما يتعلق بسلطان البلاد؛ فهو رئيس الدولة والممثل الأسمى لها، والقائد الأعلى، ذاته مصونة لا تمس، واحترامه واجب، وأمره مطاع، وهو رمز الوحدة الوطنية، والساهر على رعايتها وحمايتها، ذلك ما ما أكدته

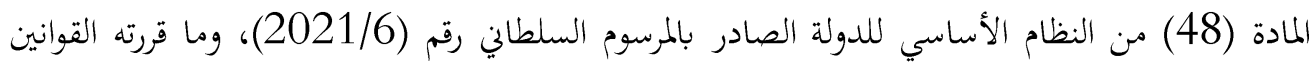
ذات الصلة، لا سيما من خلال التشديد على حقوقه وحرمة حياته وذاته وسلطاته، وفق ما أكد عليه قانون

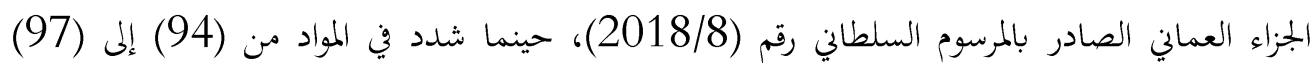
على حرمة التعرض على حياة السلطان وسلامة جسده وحقوقه وسلطته وذاته فضلا عن أداء عمله

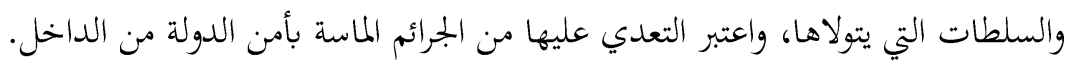


أما ما يخص حصانة رؤساء الدول الأجنبية ومثثليها حال تواجدهم في إقليم السلطنة، فإن سلطنة عمان وباعتبارها جزء من الجمتمع الدولي وعضو فاعل في هيئة الأمم المتحدة وعدد كبير من التجمعات والمنظمات الدولية الأخرى؛ فقد وقعت على العديد من الاتفاقيات والمعاهدات الدولية في مجال توطيد علاقتها مع مع مئه دول العالم الأخرى من جهة وحماية حقوق الإنسان من جهة أخرى ابتداء من ميثاق الأمم المتحدة المبرم

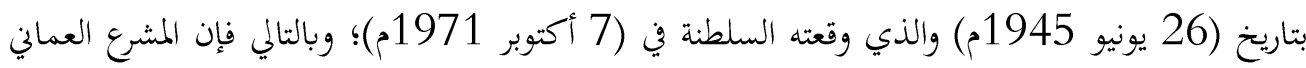
قد عنى أيما عناية بإضفاء حماية خاصة لرؤساء وممثلي الدول الأجنبية حال تواجدهم في إقليم السلطنة، من خلال الحصانة التي قررها لهم بموجب توقيعه على الاتفاقيات والمعاهدات الدولية المنظمة لذلك من جهة،

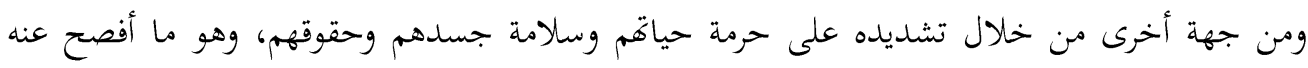

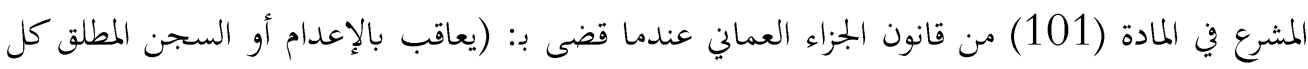

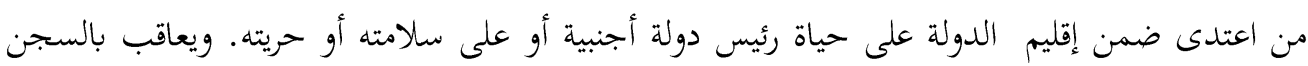
مدة لا تقل عن ثلاث سنوات ولا تزيد على خمس عشرة سنة إذا لم ينتج عن الاعتداء تمديد لحياته)، كما

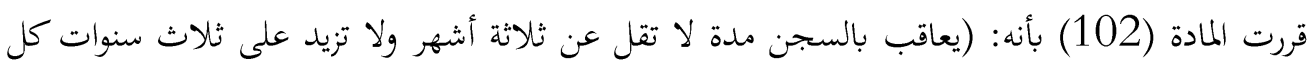
من ارتكب علانية طعنا في حق رئيس دولة أجنبية في أثناء وجوده في إقليم الدولة، أو ممثل دولة أجنبية معتمد لدى الدولة أو عاب أيا منهما في ذاته).

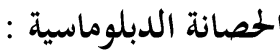

الحصانة الدبلوماسية هي مهد الحصانات وأساسها، قررةا الحضارات القديمة والشريعة الإسلامية إيمانا بأهمية الرسل والمبعوثين في توطيد العلاقات بينها، ونظمتها التشريعات المعاصرة كأساس للعلاقات الدولية، انطلاقا

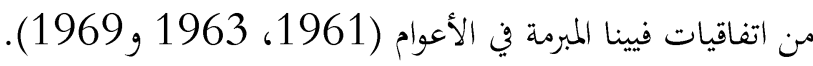

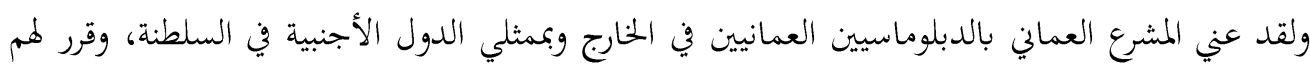
من وسائل الحماية والضمانات، بما يكفل قيامهم بأعمالهم على الوجه المناط بكم، وذلك إيمانا منه بأهمية

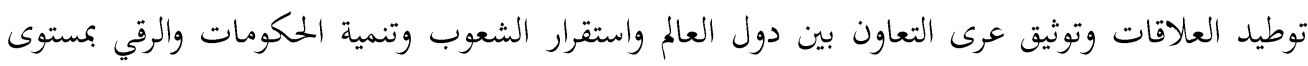

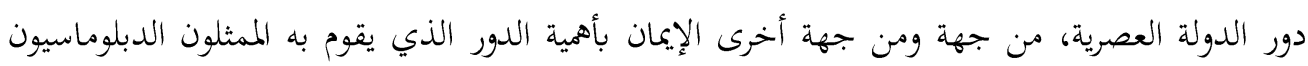
والقنصليون في تحقيق ذلك. لذلك كان أول ما حرص عليه المشرع العماني في بداية النهضة المباركة هو السير على ذلك النهج، فما كان منه إلا أن قرر انظمام السلطنة لتلك الاتفاقيات والتوقيع عليها الذي كان بتاريخ (31 مايو 
1974م)، كما أنه أصدر قانونا خاصا عنى بتنظيم وزارة الحنارجية، صدر بموجب المرسوم السلطاني رقم (2008/32)، وفيه عرَّف الدبلوماسيين بأفم: (الموظفون الذين يشغلون وظائف دبلوماسية أو قنصلية). ومن ذلك المنطلق؛ فقد قررت المادة (16) من قانون الجزاء العماني بأنه: (مع عدم الإخلال بالاتفاقيات والمعاهدات التي تكون الدولة طرفا فيها، لا تسري أحكام هذا القانون على: أ- .. ب- الجرائم التي يقترفها موظفو السلك الدبلوماسي والقناصل الأجانب وهم متمتعون بالحصانة التي يخولمم إياها القانون الدولي

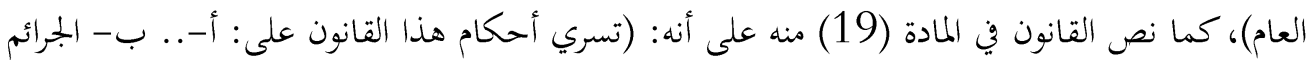
التي يقترفها موظفو السلكين الدبلوماسي والقنصلي العمانيون في الخارج وهم متمتعون بالحصانة الدبلوماسية بمقتضى الاتفاقيات الدولية). وبالوقوف على المادتين أعلاه نجد أن القانون قد فرق بين حالتين: الأولى موظفو السلكين الدبلوماسي والقنصلي الممثلين للسلطنة في الخارج، فهم متمتعون بالحصانة في إقليم الدول الأجنبية أثناء أداء مهام عملهم في تلك الدول، إذ لا يمكن مساءلتهم بموجب قوانين تلك الدول، وذلك وفق ما قررته الاتفاقيات والمعاهدات الدولية، إلا أن تلك الحصانة لا تعفيهم من العقاب، وإنما يطبق عليهم قانون الدولة العمانية، وهو ما أكدت عليه المادة المشار إليها بعاليه، من سريان أحكام قانون الجزاء العماني عليهم. أما بالنسبة لموظفي السلكين الدبلوماسي والقنصلي الممثلين للدول الأجنبية في السلطنة، فإِهم متمتعين بالحصانة، ولا يمكن تطبيق نصوص القانون الجزائي العماني عليهم، وقد يساءلوا بموجب القانون الوطني حسب تنظيم وقوانين كل دولة.

وفي ذلك الإطار؛ قد تثور عدة تساؤلات تتعلق بحالة فيما لو اقترف دبلوماسيو وقناصل الدول الأجنبية لأي جريمة في السلطنة، فكيف يتم التعامل معهم؟ وهل يقتصر ذلك على القضاء الجزائي فقط؟ بمعنى في

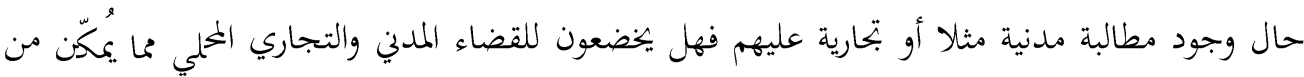
رفع دعوى عليهم في المحاكم المحلية؟. وفقا للقواعد العامة فإن الحصانة التي يتمتع بها موظفو السلكين الدبلوماسي والقنصلي تمنع خضوعهم للقضاء المحلي الجنائي والمدني والإداري، بحسب طبيعة العلاقة والخلاف الواقع، إلا أن تشريعات الدول تفاوتت في تنظيمها ذلك، فمنها من ضيقت وحصرت الحصانة في القضاء الجنائي فقط، ومنها من وسعت وشملت بها القضاء المدني والإداري أيضا، ذلك من جانب ومن جانب آخر تفاوتت التشريعات في اعتبار أي الأعمال التي تدخل في نطاق الحصانة، فمنها من حصرها في الأعمال الرسمية وهي التي يرتكبها الموظف أثناء مباشرته عمله أو بمناسبته ومنها ما شملت بها كل الأفعال التي يرتكبها الدبلوماسي أو القنصلي، إلا أن 
اتفاقيات فيينا الموقعة عام 1961 و1963 و1969 حسمت الجدل بشمول حصانة الدبلوماسي لكل الأعمال المرتكبة منه ما عدا بعض الممارسات البسطية مثل دعاوى تملك العقار ودعاوى الإرث والتركة

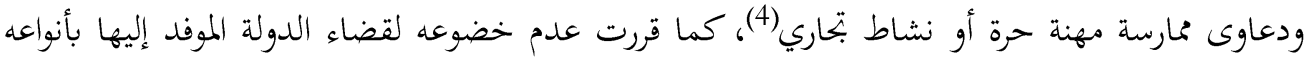
الثلاثة.

وباستقراء نصوص التشريعات العمانية؛ نجد أها اقتصرت على تنظيم الحصانة في القانون الجزائي فقط، بينما لم ينص صراحة في أي من أفرع القانون الأخرى على مدى خضوع الدبلوماسي والقنصلي للقضاء الإداري

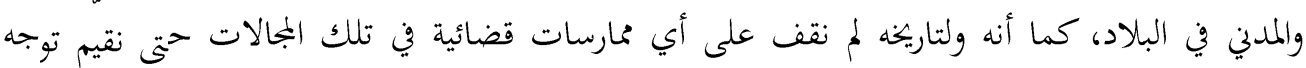

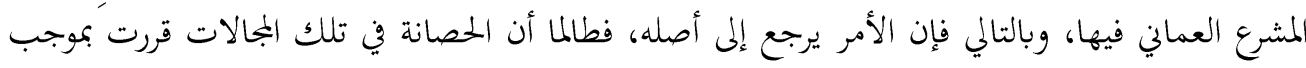

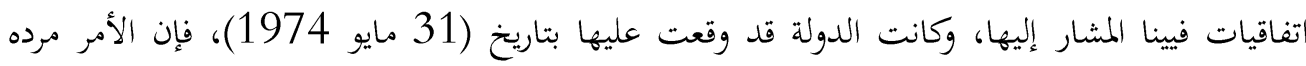
لأحكام تلك الاتفاقيات باعتبارها ملزمة للقضاء العماني، وفق ما تم الإشارة إليه أعلاه.

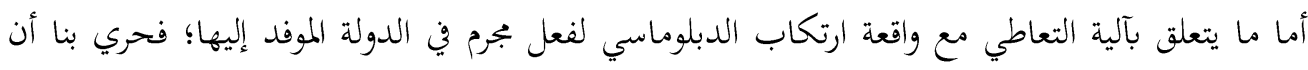

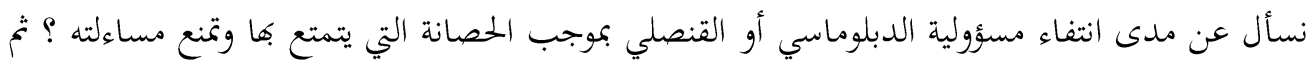
إنه ما هو الخيار المتاح للدولة الموفد إليها حال ارتكابه جريمة في نطاق إقليمها الجغرافي؟

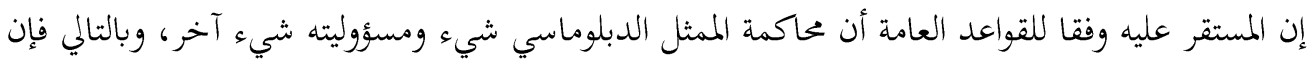

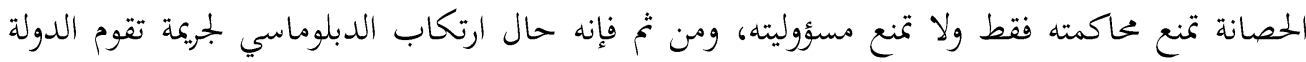

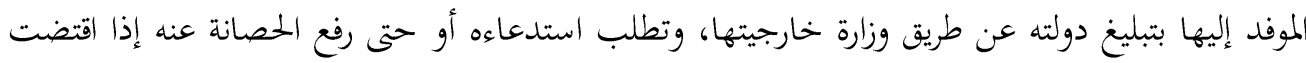

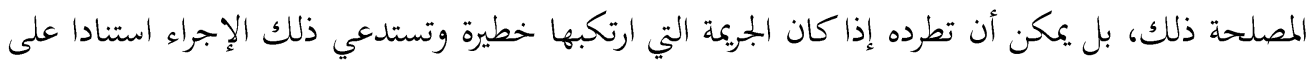

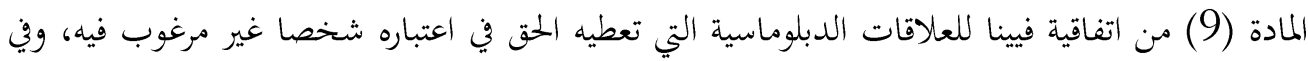

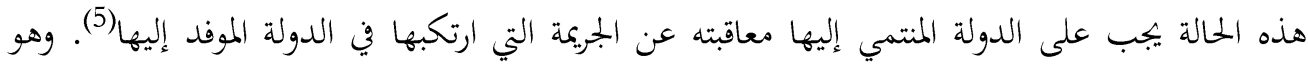

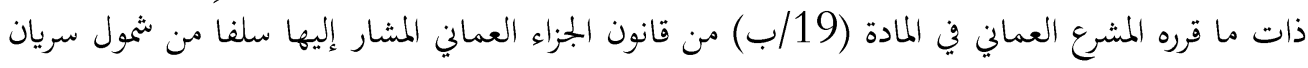
القانون وتطبيقه على ممثلي السلكين الدبلوماسي والقنصلي العمانيين في الخارج.

الخصانة القضائية:

ينصرف مفهوم السلطة القضائية وفق القواعد العامة عموما والمشرع العماني خصوصا إلى القضاة، سواء

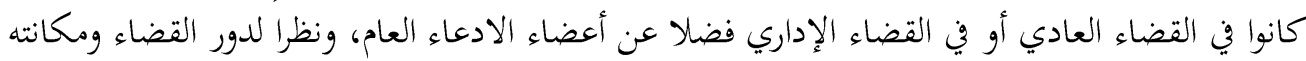
الرفيعة في الدول فقد حرصت دساتير العالم على صون هيبته ورعي كرامته وتقدير رفعته والسعي لإحاطته بأكبر قدر ممكن من الوسائل والأدوات لتسهيل مهمته وضمان حيان حياده ونزاهته واستقلاله. 
ولاشك أن المشرع العماني قد حرص أيما حرص على استقلال القضاء في البلاد باعتباره ركيزة أساسية على

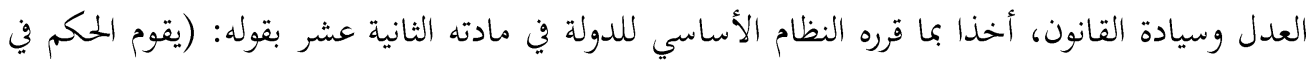
الدولة على أساس العدل والشورى والمساواة...)، فالعدل هو أساس الحكم والملك، وعليه ولا شيء غيره تقوم الدولة بأكاها وتنهض الحكومة بواجباتا، لذلك جاءت المادة (76) من النظام الأساسي مؤكدة على ولى أنه: (سيادة القانون أساس الحكم في الدولة، وشرف القضاء ونزاهة القضاة وعدلهم ضمان للحقوق والحريات)، وفي سبيل ذلك رعى المشرع استقلال السلطة القضائية وأكده بما قرره في المادة (77) من النظام ونسه الأساسي بقوله: (السلطة القضائية مستقلة وتتولاها المحاكم على اختلاف أنواعها ودرجاتما تصدر أحكامها

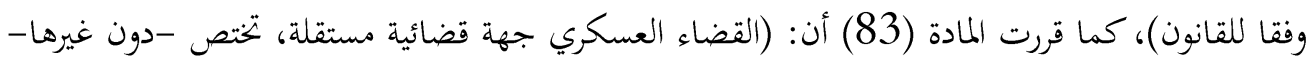
بالفصل في كافة الجرائم العسكرية التي تقع من منتسبي القوات المسلحة، وقوات الأمن، وذلك على النحو الذي يبينه القانون)، وفي ذات السياق أكدت المادة (86) على أن الادعاء العام جزء من السلطة القضائية القئية بقولها: (الادعاء العام جزء من السلطة القضائية، يتولى الدعوى العمومية باسم الجمتمع، ويشرف على شؤون

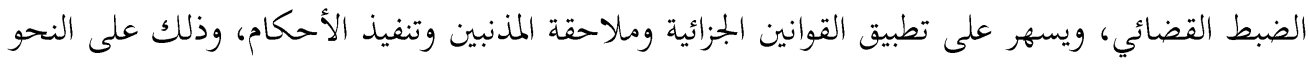
الذي يبينه القانون). ولما كان المشرع العماني قد أكد على استقلال السلطة القضائية؛ فمن الطبيعي أن يكفل لها من الضمانات

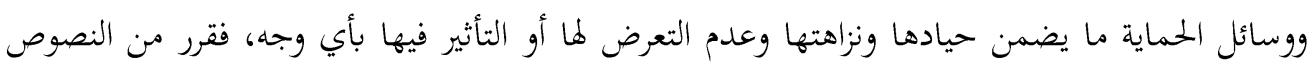

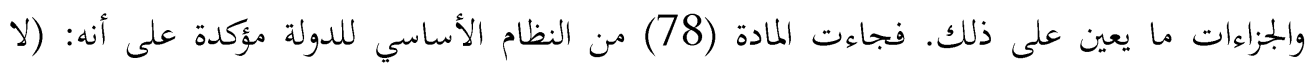
سلطان على القضاة في قضائهم لغير القانون، وهم غير قابلين للعزل إلا في الحالات التي يحددها القانون، ولا يجوز لأي جهة التدخل في القضايا أو في شؤون العدالة، ويعتبر هذا التدخل جريمة يعاقب عليها

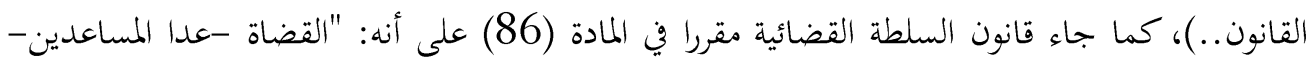
غير قابلين للعزل إلا في الحالات ووفقا للإجراءات المنصوص عليها في هذا القانون..."، ثم جاءت المادة (87) بالنص على: "في غير حالات التلبس بالجريمة، لا يجوز إلقاء القبض على القاضي أو حبسه احتياطيا

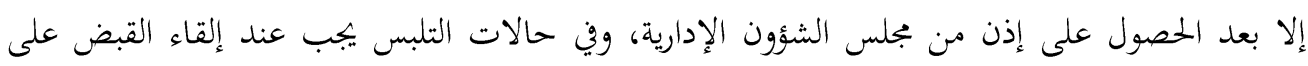

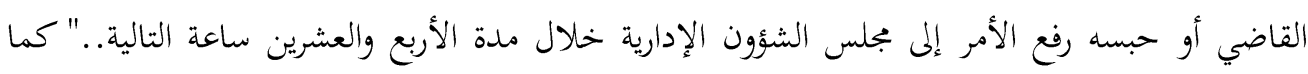
نصت المادة (88) على أنه: "لا يجوز اتخاذ إجراءات التحقيق أو رفع الدعوى العمومية على القاضي إلإديا

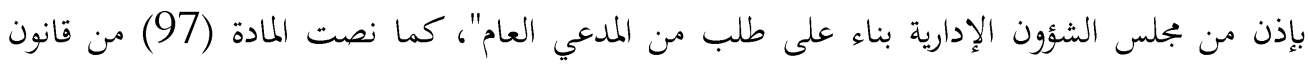
محكمة القضاء الإداري الصادر بالمرسوم السلطاني رقم (99/91) على أنه: (أعضاء المحكمة من وظيفة 
قاض فما فوقها غير قابلين للعزل إلا في الأحوال وبالإجراءات المنصوص عليها في هذا القانون)، كما نصت المادة (98) على أنه: (في غير حالات التلبس بالجريمة، لا يجيوز إلقاء القبض على عضلى عضو المحكمة أو حبسه

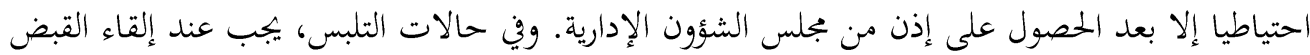

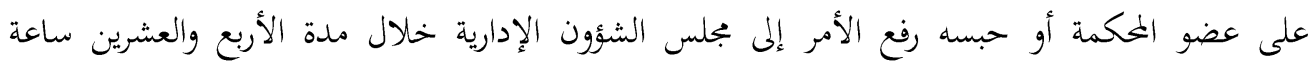
التالية).

وعليه؛ فبالنظر لعموم النصوص القانونية السابقة نجد أن المشرع العماني قد ارتكن في معرض تقريره

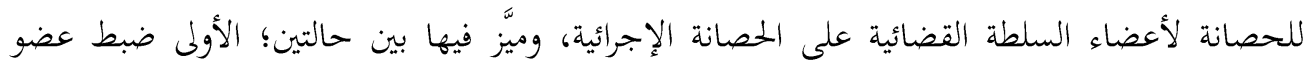
السلطة القضائية في حالة تلبس بجرم مشهود، وهنا يتم القبض عليه وحبسه، إلا أنه يجب رفع الأمر لمجلس

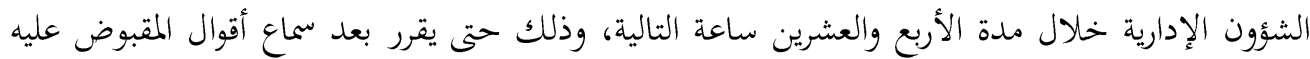

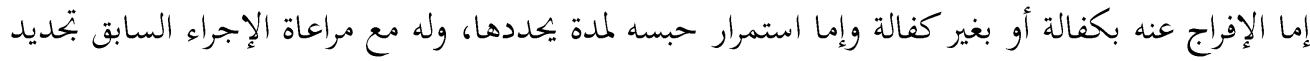

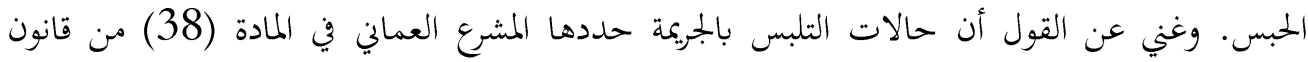
الإجراءات الجزائية: (تعتبر الجريمة متلبسا بها في الأحوال الآتية: 1- حال ارتكاب الجريمة. 2- عقب

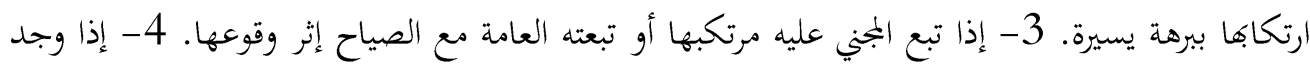

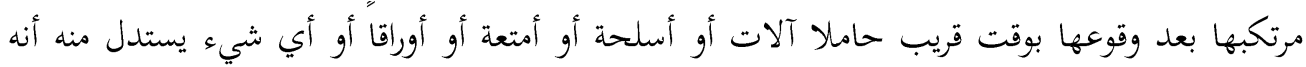
فاعل أو شريك في الجريمة أو إذا وجدت به في هذا الوقت علامات أو آثار تفيد ذلك).

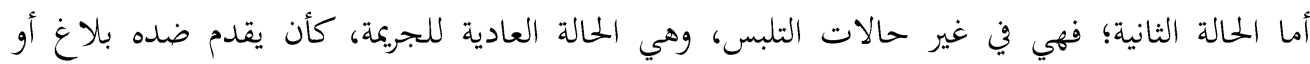

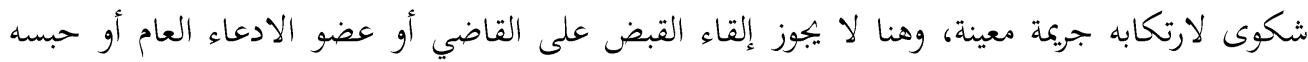

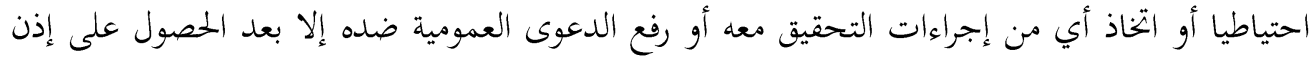

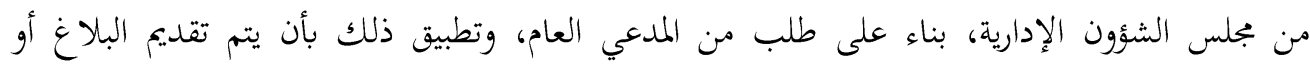
الشكوى لأي من مأموري الضبط القضائي وفق ما قررته المادة (33) من قانون الإجراءات الجزائية، ثم

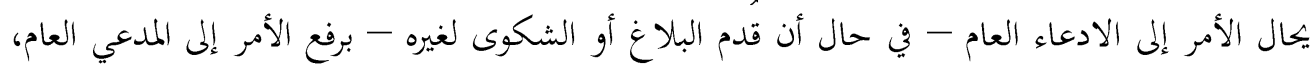

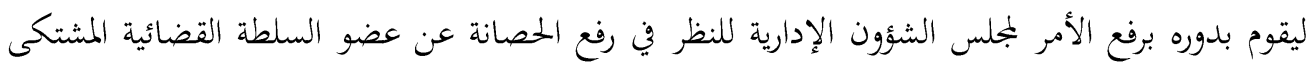
عليه من عدمه.

ولاشك أن القيد الوارد أعلاه هو ذات ما عنته المادة (5/2) من قانون الإجراءات الجزائية، عندما قررت

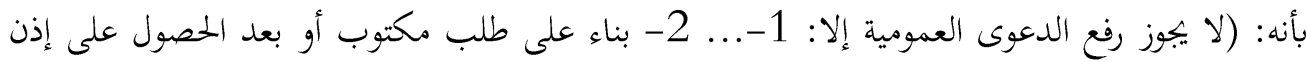
كتابي من الجهة المختصة في الجرائم التي يشترط فيها القانون ذلك)، وبالتالي فإن ذلك وكما أشرنا سلفا 
استثناء من سلطة الادعاء العام في تحريك الدعوى العمومية ورفعها، إذ تغل يده عن مباشرة أي إجراء في مثل الحالات أعلاه إلا بعد الحصول على الإذن من بجلس الشؤون الإدارية للقضاء، ومن ثم فإنه في حال رفع الدعوى بغير تلك الطريقة ودون استيفاء ذلك الشرط يبطل الإجراءات وعلى القاضي المختص حينها القضاء بعدم قبول الدعوى لرفعها بغير الطريق القانوين، وفق ما سبق الإشارة إليه في التكييف الفقهي للحصانة والطبيعة القانونية لها، وهو ذات ما سار عليه القضاء العماني في عدد من الأحكام الصادرة له.

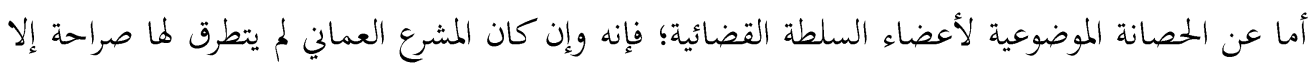
أنه معلوم وفق القواعد العامة والأحكام الفقهية أن أعضاء السلطة القضائية يتمتعون بحصانة مطلقة فيما يتعلق بقضائهم وأعمالهم، فلا يمكن مساءلتهم عن أخطائهم في تطبيق العدالة والقانون وإن كان سلوكهم خاطئا، غير أن من الفقهاء من قارب الحصانة الموضوعية تلك بأحكام المخاصمة وهي المتعلقة بمسؤوليتهم المدنية عما ارتكبوه من أخطاء في قضائهم وتطبيقهم للقانون، والتي نص عليها المشرع العماني في المادة (329) من قانون الإجراءت المدنية والتجارية وجاء نصها: (بتوز مخاصمة القضاة وأعضاء الادعاء العام في الأحوال الآتية: أ- إذا وقع من القاضي أو عضو الادعاء العام في عملهما غش أو تدليس أو خطأ مهني

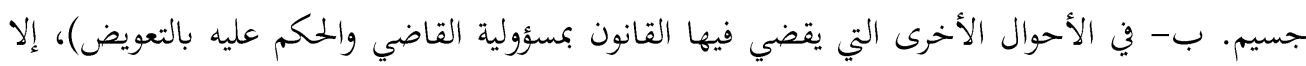

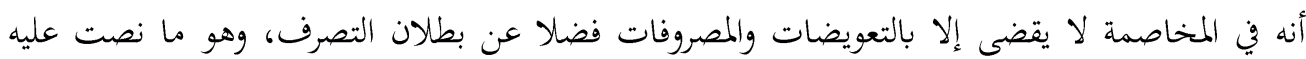
المادة (332) من قانون الإجراءات المدنية والتجارية العماني مقروءة: (... وإذا قضي بصحة لإنهات المخاصمة

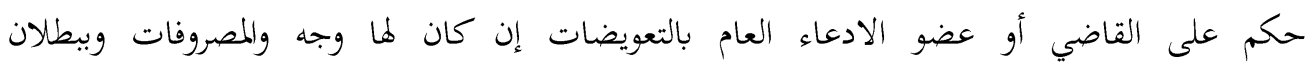

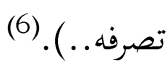

ولئن كانت نصوص قانوني السلطة القضائية ومحكمة القضاء الإداري قد نصت على الأحكام المتعلقة بالحصانة وإجراءات رفعها بالنسبة للقضاة، على خلاف قانون الادعاء العام الذي لم يأتي بذكر أحكام اللحصانة بالنسبة لأعضاء الادعاء العام، إلا أن المادة (9) من قانون الادعاء العام قد نصت على على أنه: (تسري بشأن أعضاء الادعاء العام -عدا معاوني الادعاء العام- الأحكام المتعلقة بالحصانة القضائية وإجراءات رفعها التي ينص عليها قانون السلطة القضائية)، ومن ثم فإن كل ما يسري على القضاة في أحكام الحصانة وإجراءات رفعها يسري أيضا على أعضاء الادعاء العام. الحصانة البرلمانية : الحمان معلوم أن البرلمان هو هيئة أو مجلس تشريعي يمثل الشعب في الحكومة، وتختلف مسمياته من دولة إلى أخرى من برلمان إلى مجلس نواب أو مجلس أمة أو مجلس شورى أو مجلس دولة أو غير ذلكئك، وله صله صلاحيات محددة 
تختلف بين دولة وأخرى بحسب نظام كل دولة، وفي سلطنة عمان ينصرف مفهوم البرلمان إلى مجلس عمان بشقيه مجلس الدولة وبجلس الشورى، حيث نصت المادة (68) من النظام الأساسي للدولة على أنه: (يتكون مجلس عمان من الآتي: بجلس الدولة -بجلس الشورى)، ثم جاءت المواد التالية لذلك في النظام

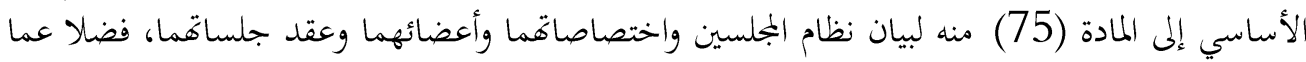
جاء من تفصيل وبيان لنظام عمل بجلس عمان في قانون مجلس عمان الصادر بالمرسوم السلطاني رقم

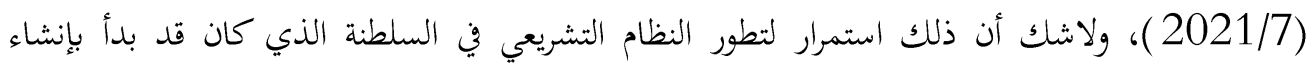
مجلس الشورى بموجب المرسوم السلطاني رقم (91/94)، وصدور لائحته الداخلية بموجب المرسوم السلطاني رقم (91/97)(7) التي كانت هي أول من قرر ونظم الحصانة البرلمانية في التشريع العماني، ثم

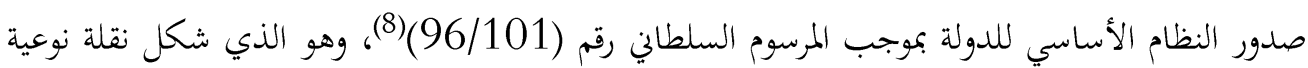
للنظام التشريعي في السلطنة من خلال إقراره لنظام المجلسين(9)، تلاه صدور المرسوم السلطاني رقم

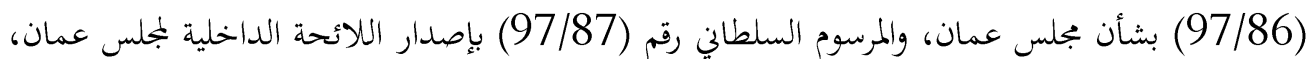
ثم المرسوم السلطاني رقم (97/88) بشأن إصدار اللائحة الداخلية لمجلس الشورى وألغيت بموجبه اللائحة السابقة، ثم وفي سنة 2011م صدر المرسوم السلطاني رقم (2011/99) بإجراء بعض التعديلات على إنى النظام الأساسي السابق للدولة والذي قرر فيه صلاحيات أوسع لعمل المجلسين، بعدها صدر قانون انتخابات أعضاء بجلس الشورى الصادر بالمرسوم السلطاني رقم (2013/58). وبتتبع المراسيم واللوائح المشار إليها ؛ نجد أن المادة (3) من اللائحة الداخلية لمجلس الدولة الصادرة بالمرسوم المباء

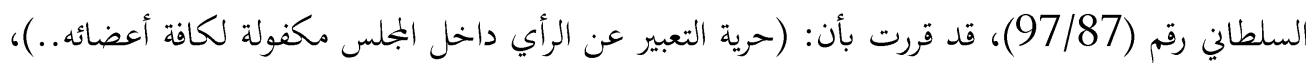
ونصت المادة (6) من ذات اللائحة على أنه: (لا يجبوز - في غير حالة الجرم المشهود - اتخاذ أي إجراءات

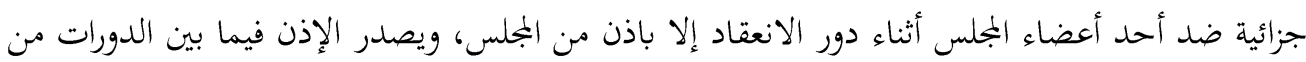
رئيس الججلس)، كما قررت المادة (4) من اللائحة الداخلية لمجلس الشورى الصادرة بالمرسوم السلطاني رقم (97/88)، على أن: (حرية التعبير عن الرأي داخل المجلس مكفولة لكافة أعضائه...)، كما نصت المانس المادة

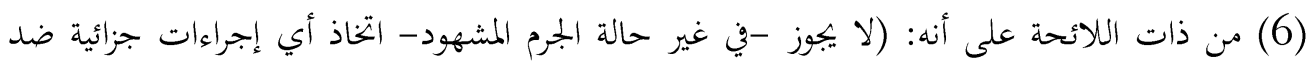

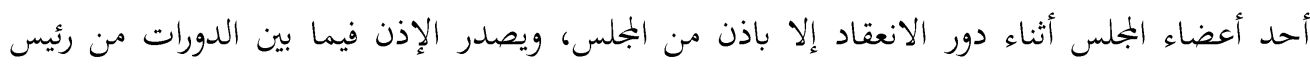
المجلس). ثم إنه وبعد صدور المرسوم السلطاني رقم (2011/99) بشأن إجراء بعض التعديلات على النظام

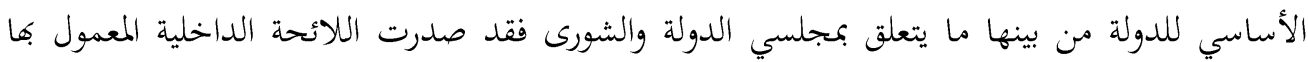


حاليا لمجلس الشورى بموجب القرار رقم (2012/1) الصادر عن بجلس الشورى، وأفردت فصلا كاملا للحصانة البرلمانية في فصلها الثالث في المواد من (23 - 30)، وقد قررت في مادتها الـ (24) على أنه: (لا يجوز في غير حالة الجرم المشهود أن تتخذ ضد العضو إجراءات التحقيق أو التفتيش أو القبض أو أو الحبس أو أي إجراء جزائي آخر إلا باذن من المجلس، وإذا لم يصدر المجلس قراره في طلب الإذن خلال

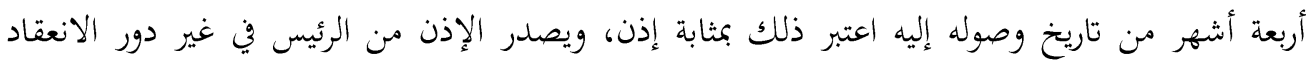

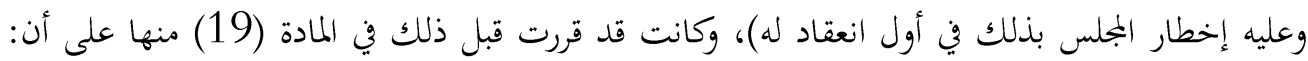
عضو المجلس حر فيما يبديه من آراء وأفكار أمام المجلس ومكتبه ولجانه في الأمور التي تدخل في إختل المجلس، ولا تبوز مؤاخذته على ذلك. وبالوقوف على النصوص أعلاه ؛ نجد أن المشرع العماني كغيره من التشريعات المعاصرة قد حرص على منح أعضاء البرلمان بصفتهم الوظيفية حصانة تضمن أداء عملهم بكل حياد ونزاهة وبعيد عن أي ضغط أو تأثير، تنصرف لكل ما يبدر عن العضو من أقوال أو أفعال أو آراء أو أفكار خلال فترة عمله بالمجلس، أثناء مباشرته لوظيفته أو بمناسبة أدائها، شريطة أن تكون من صميم اختصاص المجلس، وهي ما تعرف بون بالحصانة

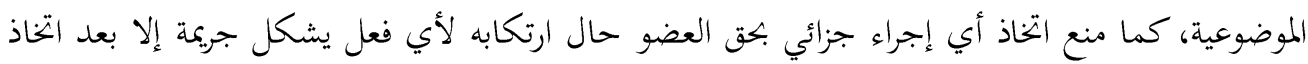

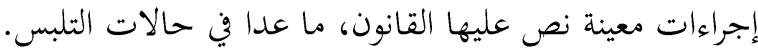

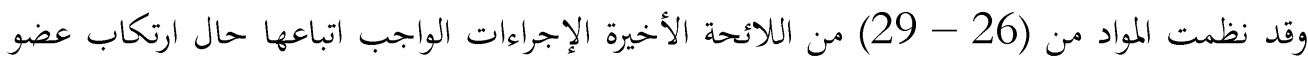
المجلس لأي جريمة، حيث نصت المادة (26) على أنه: (يقدم طلب الإذن برفع الحصانة عن العضو إلى الى

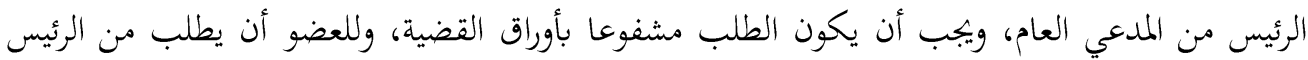

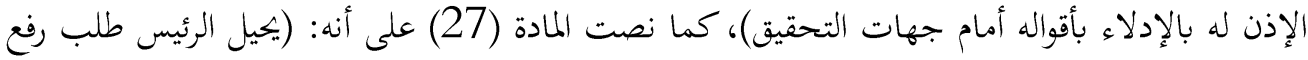
الحصانة إلى اللجنة التشريعية والقانونية بالمجلس لدراسته وإبداء الرأي فيه في مدة لا تزيد على شهر وإخطار المجلس بذلك في أول جلسة تالية، ويعرض الرئيس تقرير اللجنة على المجلس، وعلى اللجنة أن تدعو العضو

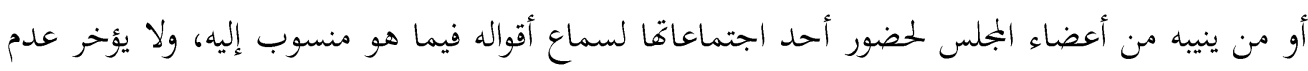

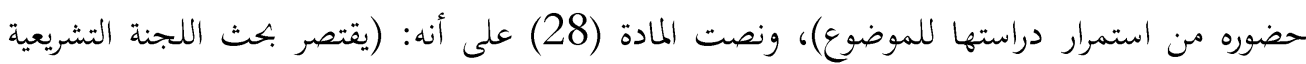
والقانونية والمجلس فيما إذا كانت الدعوى كيدية أو يقصد بها منع العضو من أداء واجبه بالمجلس، ولا ينظران في توفر أدلة الإدانة من عدمه، ومتى تبين جدية الدعوى يصدر المجلس الإذن برفع الحصانة)، وجاءت المادة (29) مقررة: (يصدر المجلس قراره برفع الحصانة من عدمه بعد مناقشته في ضوء تقرير اللجنة

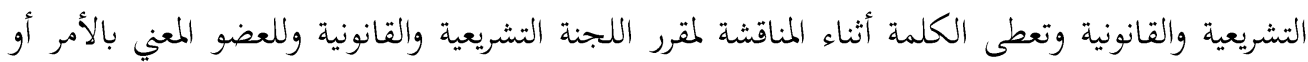


من ينيبه من الأعضاء، ثم لعضوين آخرين أحدهما مؤيد لرفع الحصانة والآخر معارض لذلك، ويصدر المجلس قراره بأغلبية أعضاء المجلس الحاضرين، ويتم التصويت على ذلك بطريقة سرية في عدم وجود العضو داخل قاعة المجلس أثناء التصويت). ويتجلى من ذلك أن الحصانة البرلمانية في الأساس ما هي إلا حصانة مؤقتة وقيد إجرائي يؤخر التخاذ

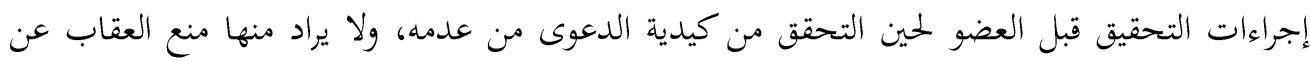
عضو البرلمان أو النظر في مدى توفر الأدلة ضده من عدمه، التي هي اختصاص أصيل لجهات التهن التحقيق وقاضي الموضوع حال رفع الدعوى. وأما في حالة التلبس بالجرم المشهود؛ فإنه يجوز القبض على على العضو واتخاذ إجراءات التحقيق المعتادة قبله،

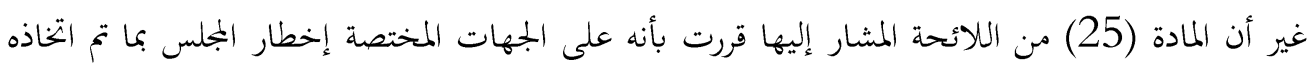
من إجراءات قضائية بحق العضو إذا ضبط في حالة جرم مشهود.

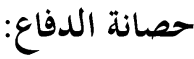
يعتبر حق الدفاع من المفاهيم الرصينة والمستقر عليها في أغلب التشريعات والأنظمة، لما له من أهمية في الحقل القضائي، وعدالة المحاكمة، لذا تدخلت جل التشريعات الوطنية للعناية بهذا الحق وإرساء مقوماته وتحقيق مستلزماته، متأثرة في ذلك بالمواثيق والمعاهدات الدولية التي تصدت لبلورة مثل هذه الحقوق، إذ أنه

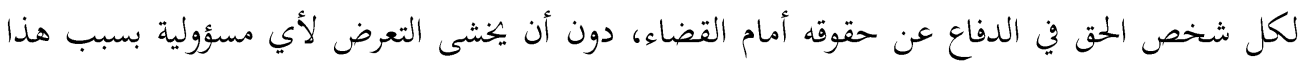
الدفاع في إطار محاكمة عادلة، وفي إطار أحكام القانون. ولما كان حق الدفع في المواد الجزائية يعد تعبيرا عن الركيزة الجوهرية للمحاكمة العادلة؛ فإنه من أكثر الحقوق الدستورية صلة بمبدأ أصل البراءة وأكثرها

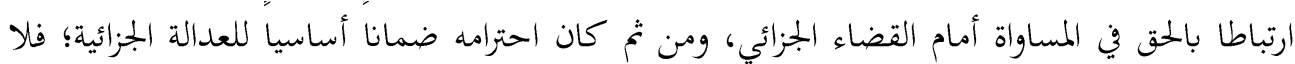
يتصور إحقاق هذه الأخيرة مع هدر حق الدفاع. وتأكيدا لذلك أولى المشرع العماني حق الدفاع أهمية بالغة، ولا تطبيق أسمى من أن ينص هم عليه في في النظام

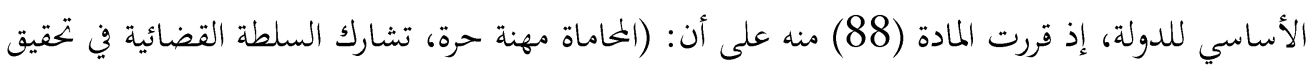

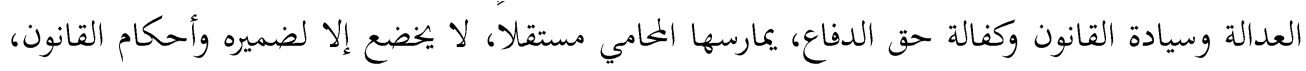

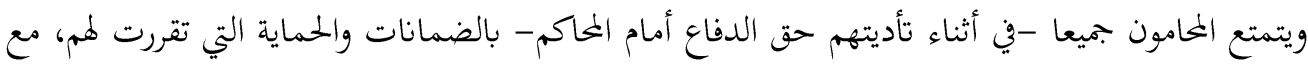
سرياها عليهم أمام جهات التحقيق والاستدلال، وذلك على النحو الذي يبينه القانون)، وتسايرت المادة الأولى من قانون المحاماة الصادر بالمرسوم السلطاني رقم (96/108) مع ذلك، مقررة بأن: (المحاماة مهنة 
حرة تشارك في تحقيق العدالة وتأكيد سيادة القانون، وذلك بكفالة حق الدفاع عن المتقاضين، ويمارس المحامون مهنتهم مستقلين لا يخضعون إلا لضمائرهم وأحكام القانون). وتطبيقا لذلك جاءت القوانين الإجرائية مؤكدة على حق الدفاع باعتباره ضمانة رئيسية للمتهم وحق أصيل لكل طرف في الدعوى، ونظمت ذلك في العديد من المواد، مثلما نص عليه قانون الإجراءات الجزائية العماني في المادة (57) بقوله: (لعضو الادعاء العام إذا اقتضت ضرورة إجراءات التحقيق أن يأمر بعدم

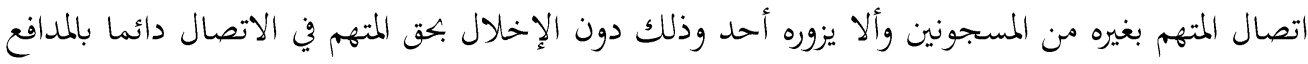
عنه)، وجاءت المادة (74) مقرة: (لكل من المتهم والمجني عليه والمدعي بالحق المدني والمسؤول عنه ومن

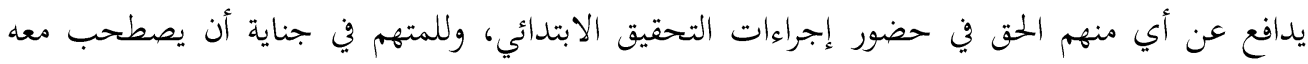
محاميا يدافع عنه..)، ونصت المادة (115) على أنه: (يجب السماح للمحامي بالاطلاع على المانى التحقيق في اليوم السابق على الاستجواب أو المواجهة، وفي جميع الأحوال لا يجوز الفصل بين المتهم ومحامية الحاضر معه أثناء التحقيق)، المادة (181): (للخصوم ووكلائهم حق حضور جلسات المحاكمة ولو كانت سرية،

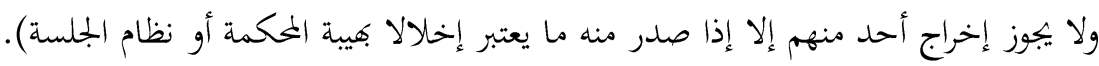

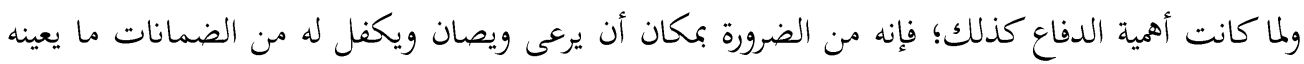
على أداء الرسالة المبتغاة منه، لذلك قرر المشرع العماني الحكيم في المادة (32) من قانون المحاماة المشار إليه

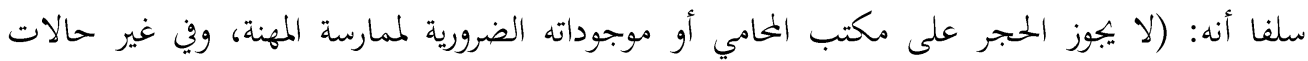

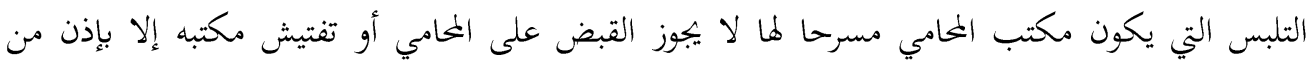
رئيس الجنة قبول المحامين). وبالنظر لذلك؛ نجد أن حصانة المحامي وفق المشرع العماني هي قيد إجرائي مؤقت يمنع القبض عليه او اتخاذ أي إجراءات تحقيق بحقه إلا بعد الحصول على إذن من رئيس للجنة قبول المحامين، وبالتالي فهي حصانة

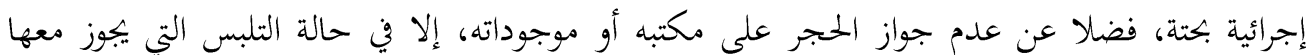

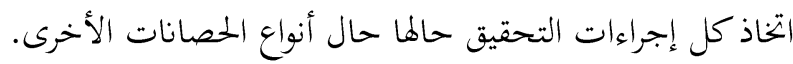
أما في الحصانة الموضوعية؛ فقد ذهبت عدد من التشريعات المعاصرة إلى النص عليها وتقريرها، وهي حصانة

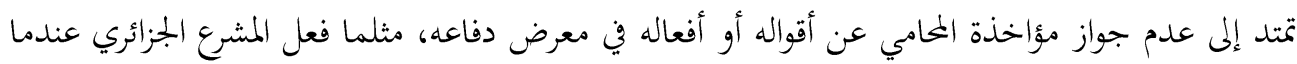
كرس حصانة الدفاع بالنسبة للمحامي في نص الفقرة الأخيرة من المادة (24) من القانون رقم (13/7) المتعلق بتنظيم مهنة المحاماة بقوله: (لا يمكن متابعة محام بسبب أفعاله و تصريحاته و محرراته في إطار المناقشة أو المرافعة في الجلسة). وفي هذا الشأن ذهب جانب كبير من الفقه إلى القول بأن عدم مسؤولية المدافع 
الجزائية ليست محض إعفاء من تطبيق القواعد القانونية، بل هي أكثر من ذلك إذ تمتد لتمحو تماما التكييف القانوني للجريمة، فلا ينسب -تبعا لذلك- للمدافع أي جريمة تصدر بمعرض الدفاع الشفوي أو الكتابي أمام الجهات القضائية مهما كانت طبيعة تلك الأنشطة والسلوكات، شريطة أن تكون طبيعة

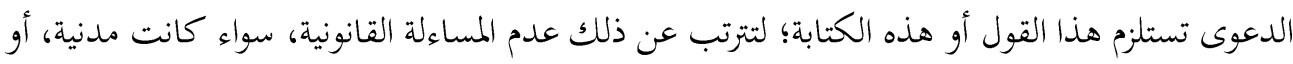

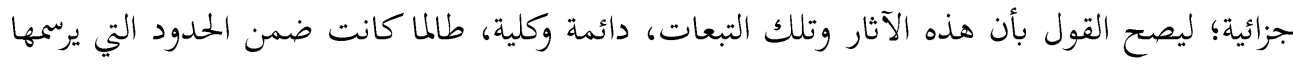

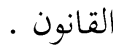

أما المشرع العماني؛ فإنه لم ينص صراحة على الحصانة الموضوعية للدفاع، كما أن الممارسات القضائية شحيحة في هذا الجانب، إلا أن الفقه قد استقر على عدم بتحيم ما يبدى في المذكرات المكتوبة أو المرافعات

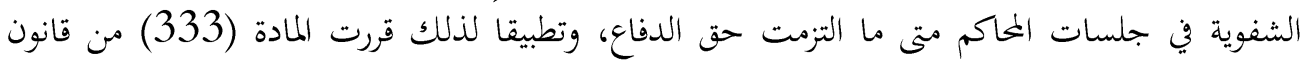

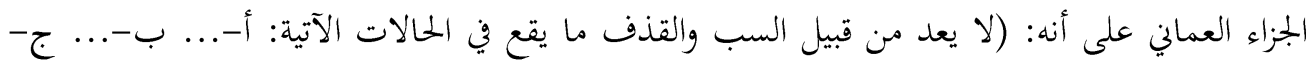

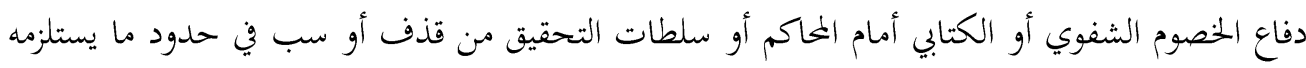
حق الدفاع). وهنا يرى الباحث؛ أنه وفي سبيل تأطير حصانة الدفاع وتنظيمها، حفظا لحقوقه من جهة

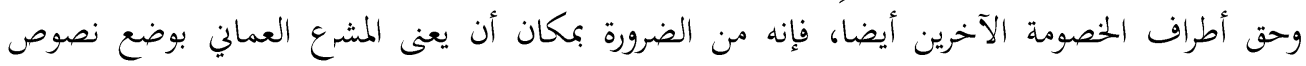
تنظيمية تتعلق بحدود الحصانة الموضوعية لحق الدفاع. حصانات أخرى : بتتبع قوانين عدد من الجهات المدنية والأمنية والعسكرية في السلطنة، وجدت أن المشرع قد قرر لموظفي

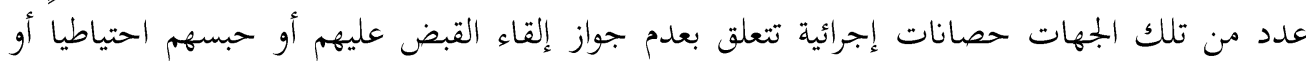

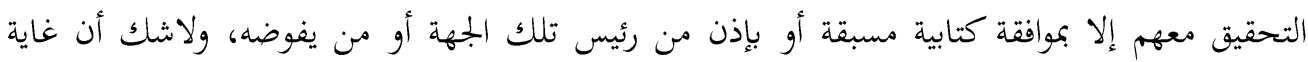

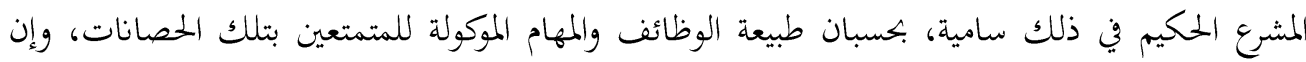

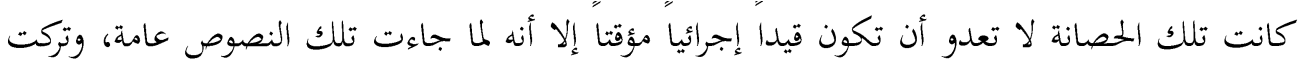
الأمر بيد رئيس تلك الجهة في الموافقة على رفع الحصانة من عدمه، وكان ذلك الإجراء هو قيد على سلطة

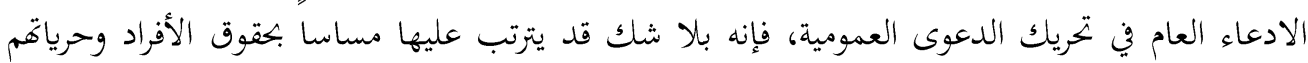
التي كفلها لهم النظام الأساسي للدولة، والتوسع في تلك الحصانات قد يحول دون اقتضاء المعتدى عليهم لحقهم ويؤثر في سير العدالة.

لذا؛ وانطلاقا من مبدأ المواطنون جميعهم سواسية أمام القانون وهم متساوون في الحقوق والواجبات العامة، الذي أقره النظام الأساسي في المادة (21)؛ يرى الباحث أنه من الضرورة بمكان أن يعيد المشرع الحكيم 
النظر في تلك الحصانات وعدم التوسع فيها وإيجاد تنظيم أكثر دقة لها حفاظا على حقوق الناس وصونا لكرامتهم.

ومن جانب آخر توجد هناك حصانات أخرى قررت بموجب الاتفاقيات والمعاهدات الدولية التي هي من أهم مصادر الحصانة، إذ قد وقعت سلطنة عمان على العديد من الاتفاقيات التي تضمنت تقرير حصانة

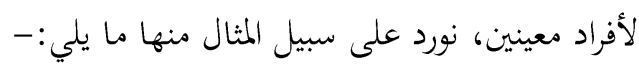

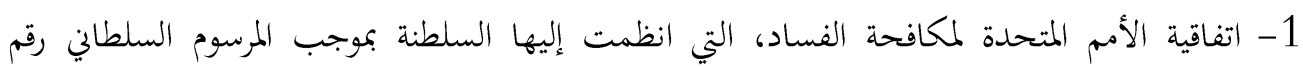

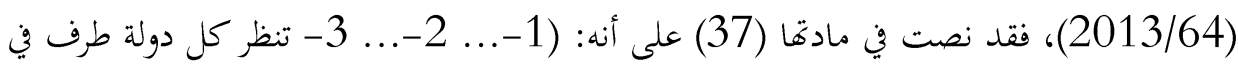

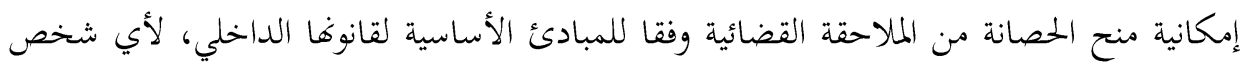
يقدم عونا كبيرا في عمليات التحقيق أو الملاحقة بشأن فعل مجرم وفقا لهذه الاتفاقية.

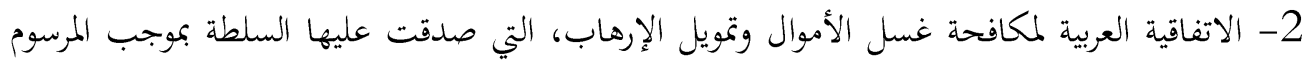

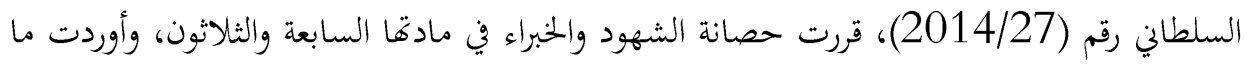
نصه: (1- لا يجوز توقيع أي جزاء أو تدبير ينطوي على إكراه الشاهد أو الخبير الذي لم يمتثل

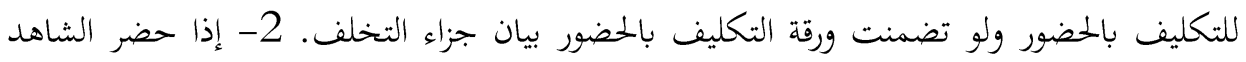

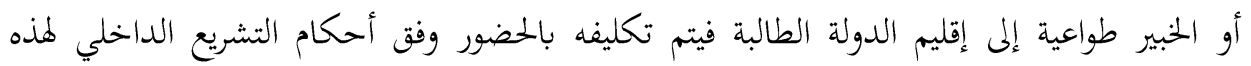
الدولة. 3- لا يجوز أن يحاكم أو يحبس أو يخضع لأي قيد على حريته في إقليم الدولة الطالبة أي

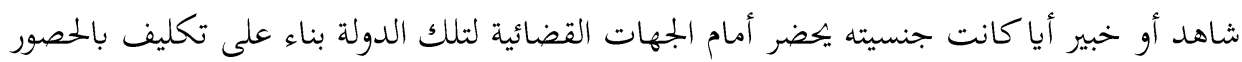

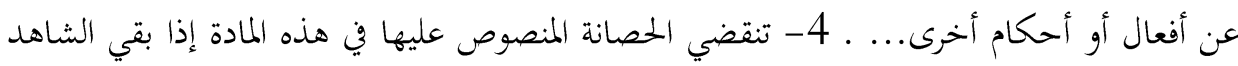

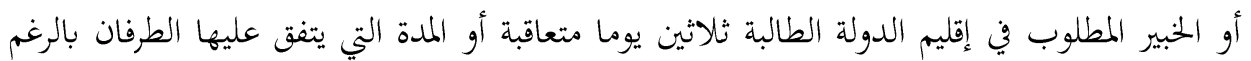
من قدرته بعد أن أصبح وجوده غير مطلوب من الجهات القضائية أو إذا عاد إلى إقليم الدولة الطالبة بعد مغادرته. 3- اتفاقية التعاون القانوين والقضائي بين حكومة سلطنة عمان وحكومة المملكة المغربية، نصت في المادة

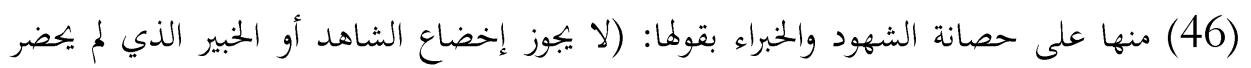

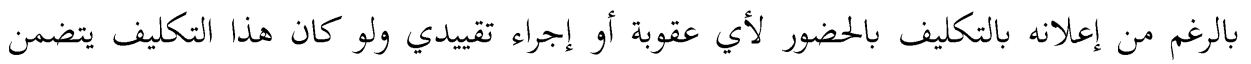

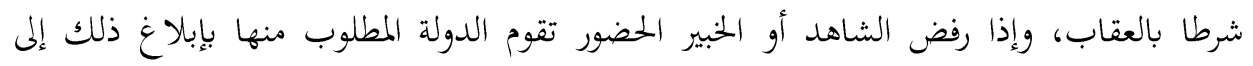

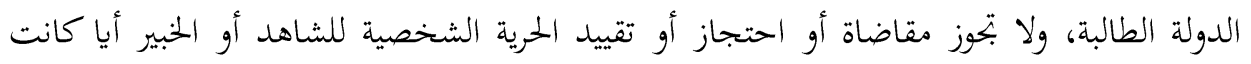

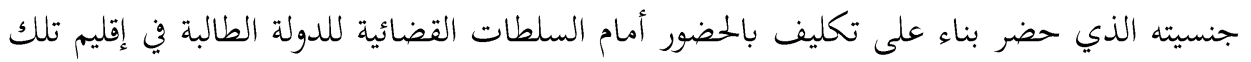


الدولة بشأن أفعال جنائية أو أحكام إدانة سابقة على مغادرته إقليم الدولة المطلوب منها، كما لا تجوز مقاضاته أو احتجازه أو معاقبته بسبب شهادته أو تقرير الحخبرة المقدم منها.

\section{المطلب الرابع: نطاق الحصانة في التشريع العماني}

لاشك أن المشرع العماني عندما قرر الحصانة بهكمته؛ فقد أرسى من القواعد المنطمة لها ما يضمن تحقيق

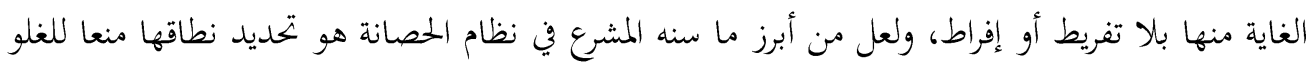
فيها أو استغلالها، والحديث عن نطاق الحصانة دائما ما ينصرف إلى النطاق الشخصي، المكاني، الزماني، والموضوعي. فبالنظر للقواعد القانونية التي قررت الحصانات بأنوعها في التشريع العماني نجد أها كحال القواعد العامة

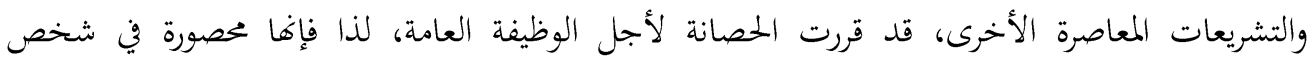
الموظف العام ذاته، ولا يمكن أن تمتد إلى أسرته أو حاشيته أو غيرهم، كما لا يمكن أن تمتد إلى المشتركين معه في الجريمة أو المتدخلين معه فيها، ومن ثم فإن النطاق الشخصي للحصانة يقتصر على شخص الموظف المونف العام فقط دون غيره. أما بالنسبة للنطاق المكاني للحصانة؛ فإن النصوص القانونية المنظمة لها لم تحدد مكان معان معينا تسري فيه

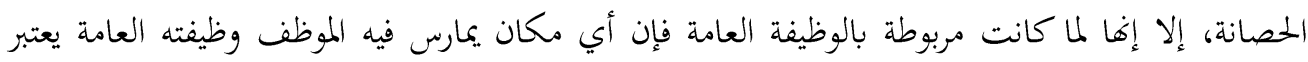
نطاقا" مكانيا" تسري عليه أحكام المصانة فيه.

وبالنسبة للنطاق الزماني؛ فإن الحصانة حق للموظف، وبطبيعة الحقوق وفق القواعد العامة تحدد بفترة بداية وفترة غاية، فتمتع الموظف بالحصانة تبدأ من تاريخ تعيينه في هذه الوظيفة، أو من تاريخ أدائه اليمين بالنسبة لأعضاء بجلس عمان وفق ما قرته المادة (23) من اللائحة الداخلية لمجلس الشورى، وتنتهي بانتهاء

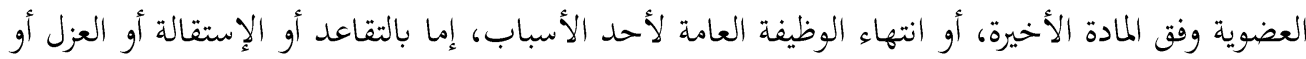

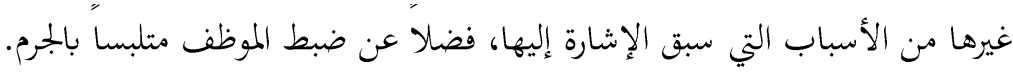
وبخصوص النطاق الموضوعي؛ فكما أسلفنا بأن الحصانة قررت للموظف بصفته الوظيفية، وبالتالي فهي تتعلق بالأعمال والصلاحيات الموكولة للموظف أثناء ممارسته وظيفته أو بمناسبتها فقط. وفي هذا الشأن؛ حسنا فعل المشرع العماني عندما وضع النقاط على الحروف، وقرر في المرسوم السلطاني رقم (2014/3) بشأن تحديد مفهوم الحصانة ونطاق تطبيقها ما يأتي: - المادة الأولى: يقصد بالحصانة التي يقررها المشرع لبعض موظفي الدولة وأعضاء المجالس المنتخبين

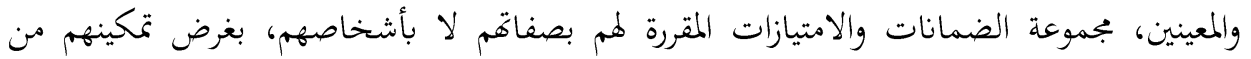


القيام بواجبات وظائفهم، أو أداء الخدمة العامة الموكولة إليهم، وليس امتيازا شخصيا بقصد إعفائهم من المسؤولية دون مسوغ.

- المادة الثانية: يقتصر نطاق الحصانة المقررة للفئات المشار إليها في المادة الأولى من هذا المرسوم على ما يصدر عنهم من أقوال وأفعال بسبب أو بمناسبة اختصاصاتم، وفي الحدود المقررة لها مكانيا وزمانيا" ووظينيا. - - المادة الثالثة: يكظر على الموظف وعضو الججلس المنتخب أو المعين إساءة استغلال الحصانة المقرة له بصفته، كما يكظر عليه استغلالها في غير الأغراض المقررة لها. ووي حال مخالفة ما تقدم يجب على الجهة أو البجلس التابع له الموظف أو العضو الاستجابة إلى طلب الادعاء العام بشأن رفع الحصانة عنه والإذن بمباشرة الدعوى العمومية واتخاذ إجراءات المساءلة الجزائية وصولا إلى تبرئة ساحته أو تمهيداء لمحاكمته. وعلى الرغم أن المرسوم أعلاه قد وضع حدا لجدل كان قائماً في الوسط الجماني بشأن الحصانة ونطاق تطبيقها، إلا أن كثير من المتتبعين والنقاد أخذ عليه" بأنه قد استند فقط على النظام الأساسي للدولة، الذي كان قد نص وقتها على حصانات محددة مثل القضائية والبرلمانية، وبالتالي فإنه لا يمكن تطبيقه على أنواع الحصانات الأخرى التي تعتبر كحصانات خاصة، كما انتهت بعض الممارسات القضائية لذات النتيجة،

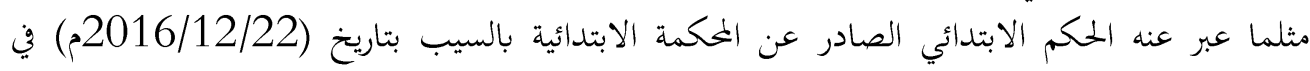
قضية جزائية عرضت عليها، وأيدته محكمة الاستئناف(10).

\section{المبحث الثاين: الإشكاليات القانونية المترتبة على الحصانة وأثرها على المسؤولية الجنائية} طالما أن الحصانة استثناء من الأصل العام القاضي بشرعية الجرائم والعقوبات والمساواة بين الأفراد أمام القانون؛ وقد يترتب عليها إفلات عدد من الجناة من العقاب أو على أقل تقدير تأخير اقتضاء حق الدولة أو المعتدى عليهم من المعتدي؛ فإنه من الطبيعي جدا أن ينتج عنها من الإشكاليات ما قد يؤثر في المسؤولية والعدالة الجنائية، ولعل ذلك قد برز في عدد من الممارسات القضائية في عدد من الأنظمة من بينها السلطنة، لهذا نادت كثير من المنظمات الحقوقية الدولية على عدم التوسع في الحصانة وتقنينها بدقة، كما حرصت الكثير من التشريعات المعاصرة على تقليل ججالات تطبيقها وآثارها، ووي سبيل الحديث عن ذلك سوف نقسم المبحث إلى مطلبين وفق ما يأتي: 


\section{المطلب الأول: الحصانات ومبدأ المساواة}

قررت المادة (21) من النظام الأساسي لسلطنة عمان أن: (المواطنون جميعهم سواسية أمام القانون، وهم متساوون في الحقوق والواجبات العامة، ولا تمييز بينهم في ذلك بسبب الجنس أو الأصل أو اللون أو اللغة

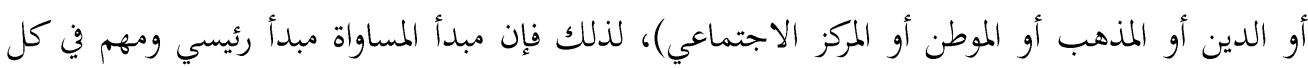
تنظيم ديمقراطي، عليه تقوم الدولة وبه تتحقق العدالة الاجتماعية، وهو ما دعا بالمشرع العماني للتقرير بها والتأكيد عليها في مادة مستقلة في النظام الأساسي للدولة باعتبارها من الحقوق والواجبات العامة.

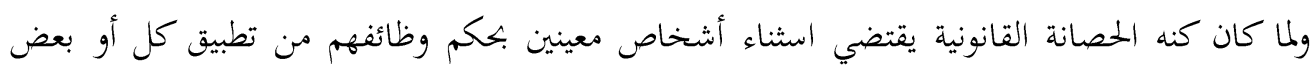

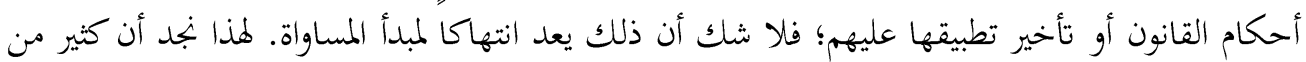
التشريعات ضيقت نطاق تطبيق الحصانة وقنتنها بأطر معينة.

\section{المطلب الثاني: الحصانات ومبدأ الشرعية الجنائية}

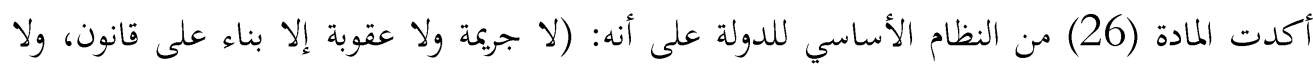

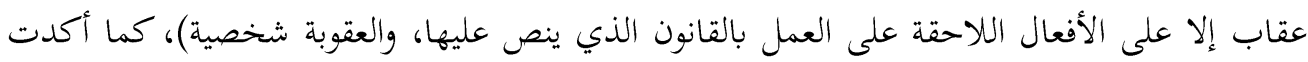

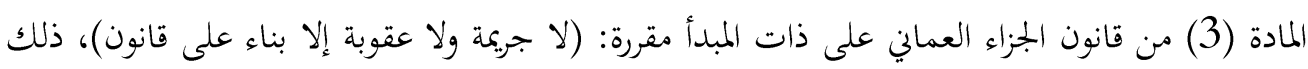

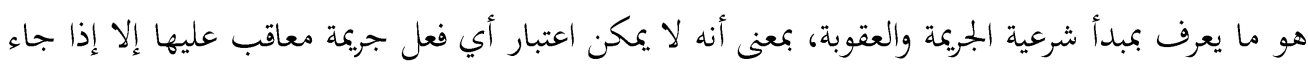
نص قانوني على اعتباره كذلك. وبالنظر للحصانة نجد أها أحد الاستثناءات الماسة بذلك المبدأ، إذا ما علمنا أن الجدل والخدلاف قائم في تحديد الطبيعة القانونية للحصانة وإسباغ التكييف المناسب لها، فبينما ذهبت آراء إلى أهنا مانع إجرائي مؤقت ذهب آخرون إلى اعتبارها مانع من موانع العقاب، كما ذهب آخرون بأها من موانع المسؤولية

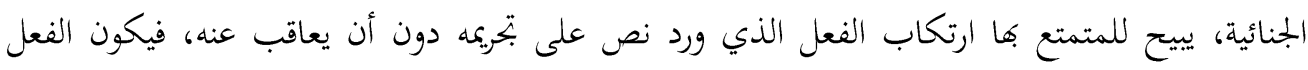

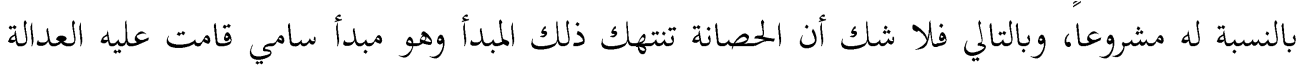

الجنائية.

وباستقراء نصوص التشريعات العمانية نجد أنه لم يرد ثمة نص صريح في ذلك، إلا أنه يمكن أن يفهم من

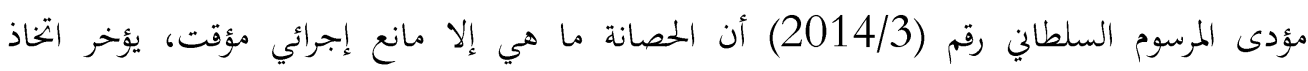

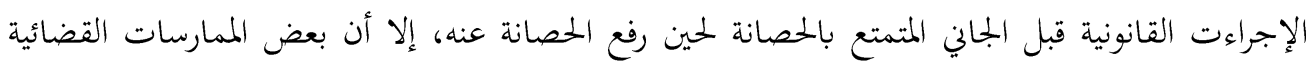

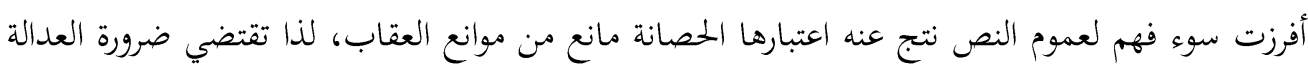
الجنائية إعادة النظر في النصوص القانونية المنظمة للحصانة. 


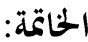

إن الحصانة تعد من القيود التي ترد على حق الادعاء العام في تحريك الدعوى العمومية، وهي وإن كانت

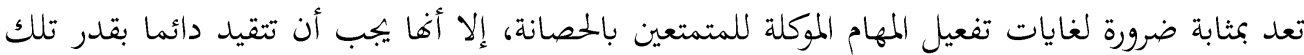
الضرورة؛ وهذا يوجب على المشرع الوطني ضرورة العمل على الحد من تلك الحصانات، وتنظيمها و تأطيرها

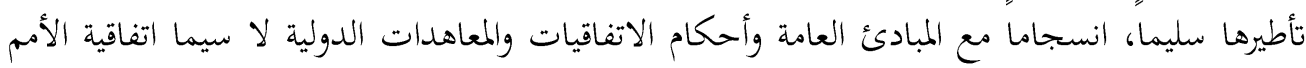
المتحدة لمكافحة الجريمة. ولاشك أن الدعوى الجزائية تعتبر وسيلة قانونية منصفة لكي يشعر المواطن بالطمأنينة بأن الجهات التي أوكل إليها المجتمع من ناحية والمشرع من ناحية أخرى مهمة ضمان المان أمنه

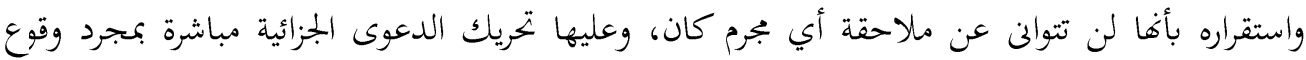
الفعل الجرمي الضار، وذلك التزام أخلاقي بالدرجة الأولى، نظرا للثقة التي أولاها المجتمع إياها، ومن منطلق ذلك؛ فإن ضرورة تحقيق العدالة والمساواة تقتضي عدم التوسع في الحصانات، وتأطيرها بنطاق الوظيفة

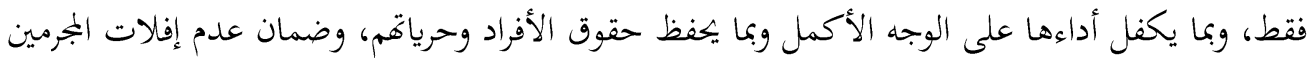
من العقاب.

\section{النتائج:}

من خلال البحث والتقصي والتطواف السابق على موضوع الحصانة؛ يخلص الباحث إلى النتائج الآتية:

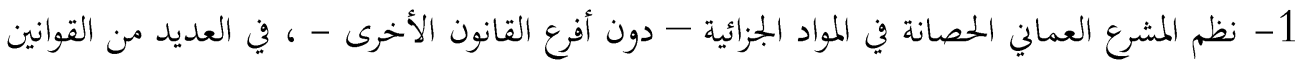

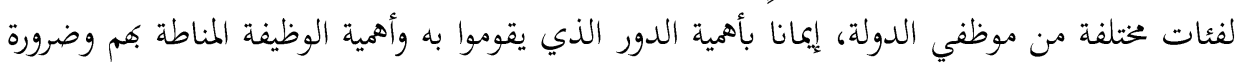

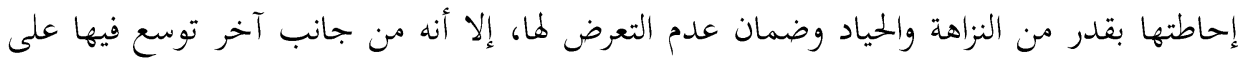
نحو لاشك أنه سوف يؤثر على مسار العدالة الجنائية والمساواة بين أفراد المجتمع.

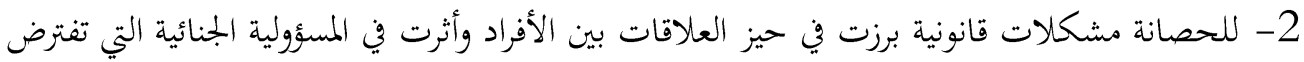

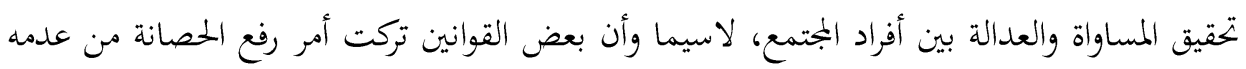

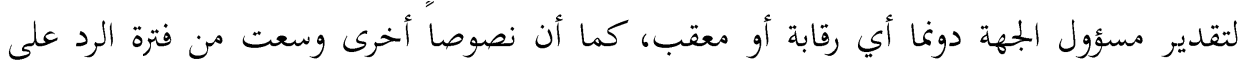
طلب الادعاء العام برفع الحصانة، مما قد يتسبب في إفلات الجاني بسبب ضياع الأدلة أو غيره، وجاءت نصوصاً أخرى بصيغة عامة ساهمت في سوء فهمها وسمحت بالاجتهاد في معرضها. 


\section{التوصيات:}

يخلص الباحث في هاية الدراسته، إلى حاجة المشرع العماني لمعالجة أوجه القصور التي شابت تنظيم الحصانة

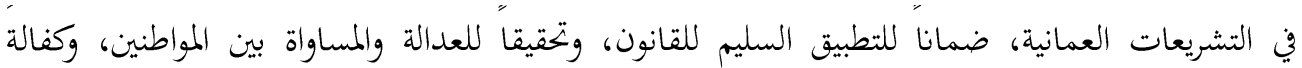
للحقوق والحريات التي نص عليها النظام الأساسي للدولة، ولعل من أبرز تلك المعالجات يما يأتي:

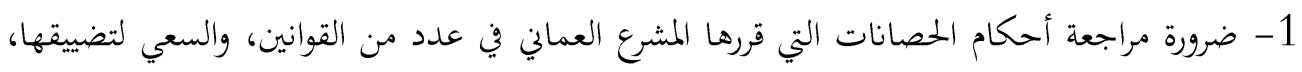
فيما تقتضيه ضرورة الوظيفة العامة ولازمة لأدائها، كما يتعين وضع مواد أكثر دقة وتنظيم في بئي بيان نطاق تطبيق الحصانة، وإجراءات رفعها. 2- من خلال ما تبين من بعض القوانين المقررة للحصانة، من ترك أمر رفع الحصانة لعموم تقدير رئيس

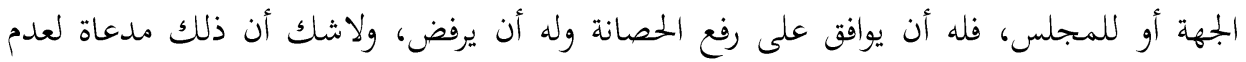
تطبيق القانون وضياع الحقوق، مما يتعين أن يكون هناك نظام معين يلزم الجهة أو الرئيس رفع الحصانة

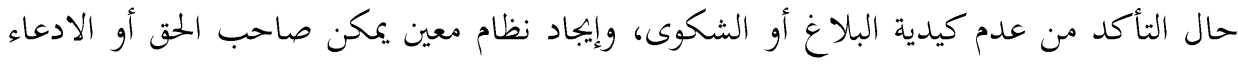
العام من التظم من قرار الجهة أو الرئيس حال رفضه طلب رئ رفع الحصانة.

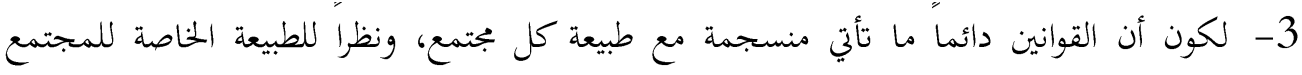

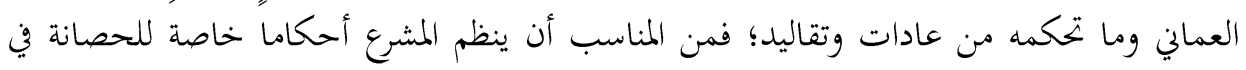
مجالات القانون الأخرى كالمدنية والتجارية وغيرها. 4- ضرورة وقوف المشرع العماني على أوجه تطبيق الحصانة في القضاء العماني، والسعي لمعالجة مشكلاهما وما يؤثر على المسئولية الجنائية للأفراد وتحقيق العدالة بينهم.

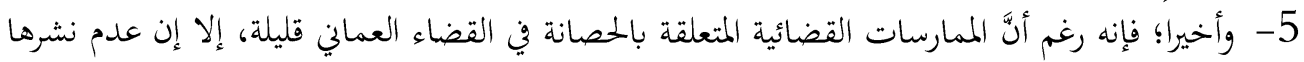
ساهم في إساءة استغلال الحصانة وتمادي المتمتعين بها في ارتكاب جرائم شخصية، فضلا عن عدم التطبيق السليم لها من جانب المشتغلين في القانون، لذا بات من الضرورة أن تعنى الممارسات القضائية والمكتبة العمانية بالحرص على نشر مثل تلك الأحكام.

$$
\begin{aligned}
& \text { المصادر: } \\
& \text { القرأن الكريع } \\
& \text { 1 1. البخاري، محمد بن إسماعيل. د.ت. صحيح البخاري. كتاب الجزية الممودعة. } \\
& \text { 2. }
\end{aligned}
$$

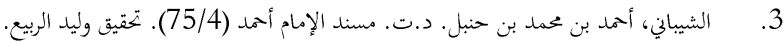

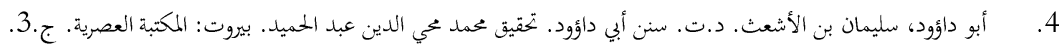

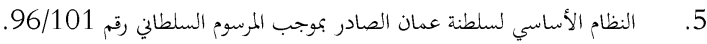




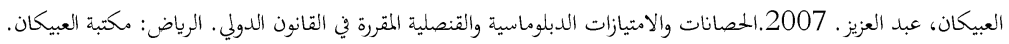

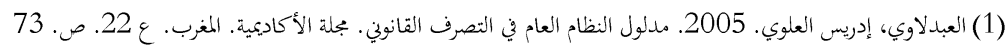

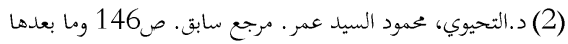




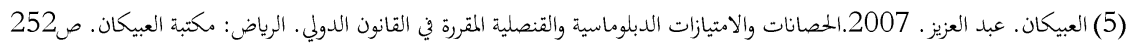

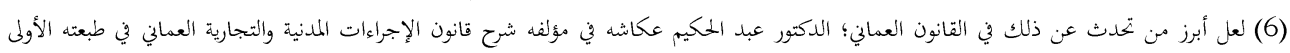

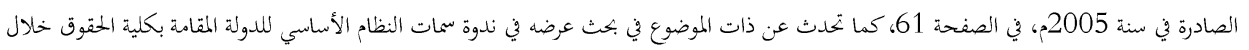

$$
\text { الفترة من (2003/10/27م - 2003/10/29). }
$$

$$
\text { (7) ألغيت بصدور لائحة جديدة بموجب المرسوم السلطاني رقم (97/88). }
$$

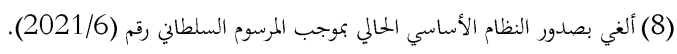

(9) أقر النظام الأساسي السابق في مادته (58 ) إنشاء مجلس عمان المكون من مجلس الدولة بأعضاء معينين من الدولة ومجلس الشورى بأعضاء منتخبين من 